\title{
La biblioteca de libros prohibidos del Consejo de la Suprema Inquisición conservada en la Biblioteca Nacional
}

\author{
Susana Cabezas Fontanilla *
}

\begin{abstract}
RESUMEN
ABSTRACT

En este trabajo se expresan las

In this work are shown the reasons, causas, motivos y protagonistas de la fundación, en el siglo xvil, de una biblioteca particular con fines muy especiales. La razón de su conservación fue tener constancia física de los libros que se prohibian, salvando un sólo ejemplar de la quema. Estas obras fueron leidas $y$ manejadas por el Consejo de Inquisición y los calificadores, para realizar las calificaciones y los indices expurgatorios. Al final, se incluye una relación de los libros editados durante el siglo Xvi pero prohibidos en diferentes épocas, añadiendo junto a sus datos bibliográficos, la signatura actual de la Biblioteca Nacional, con el objetivo de facilitar su consulta a los interesados. motives and main characters, for the foundation of a private library with specific purposes, in the XvII c. The task of its preservation was to be a material witness of the banned books, by saving only one copy from the burning. These works were read and managed by the "Consejo de Inquisicion" and the "Calificadores" to carry out their work and subsequently these books were used to compiled the "Indices Expurgatorios". At the end, a list of the published books in the Xvic., that were banned at some other time, is included, with its bibliographic details and the stamp of the National Library, with the objective to facilitate research to whom it may concern.
\end{abstract}

* Universidad Complutense de Madrid. 
La base inicial de este trabajo se conformó a partir de un Índice de libros realizado en 1848, conservado en la sección de Manuscritos de la Biblioteca Nacional, cuyo título es: Índice de libros que existían en el archivo inquisitorial procedente del Ministerio de Fomento. Cuenta con un total de 1.567 títulos pertenecientes a los siglos XVI al XIX, clasificados por el bibliotecario por orden alfabético de autor o título. Debido a la estructura interna de la Biblioteca Nacional, los libros se fueron depositando en salas diferentes, deshaciéndose el corpus y, por tanto, olvidando su procedencia.

El estudio de las librerías se ha convertido en un tema en pleno auge en toda Europa. En España, este apogeo se ha vivido sólo a medias, pues la mayoría de los estudios han sido siempre parciales, habiendo escasos trabajos amplios que los absorbieran para sacar las conclusiones oportunas. También es cierto que la publicación de estos estudios, de por sí muy específicos, se ha hecho en muchas ocasiones en revistas de difusión muy restringida, lo cual ha dificultado aún más la labor de recopilación y estudio global ${ }^{1}$.

Hasta mediados del siglo $x x$, las bibliotecas objeto de investigación eran aquéllas pertenecientes a grandes personajes, conocidos sobradamente y cuya repercusión social, política o intelectual había sido enorme. Desde entonces, las investigaciones se han centrado en librerías, cuyos dueños eran de origen más humilde o desconocida su labor pero, en cambio, representaban a la perfección su estamento social, económico o cultural. A partir de entonces han salido a la luz bibliotecas de burócratas, nobles, eruditos, artistas, libreros y mujeres ${ }^{2}$.

De estas investigaciones se deduce que durante la Edad Moderna las librerías ya no tienen el afán de exhibición de tiempos pasados. Comienzan a ser bibliotecas cuyo fin es servir para trabajo o formación intelectual de sus dueños. Por supuesto, sigue habiendo una gran demanda de libros de lujo o de exposición, pero ésta ya no es mayoritaria con respecto a la petición de libros de uso práctico. Numerosos sectores de la sociedad van ahora a formar sus propias bibliotecas privadas, que les sirven de guía para sus labores ${ }^{3}$. Los propios monarcas también formaron sus li-

\footnotetext{
- Beceiro Pita, I., «Bibliotecas y Humanismo en el Reino de Castilla: un estado de la cuestión", Hispania, 175, L/2 (1990), págs. 827-837.

DAOSON, T.J., Libros, lectores y lecturas. Estudios sobre bibliotecas particulares españolas del Siglo de Oro. Madrid 19э8. Proporciona una selecta recopilación bibliográfica relativa a estas investigaciones realizadas durante ei último siglo.

3 Fayard, J., Los miembros del Consejo de Castilla (1621-1746). Madrid 1982, pág. 469.
} 
brerías para provecho personal, donde buscaban la información necesaria para el gobierno de su estado ${ }^{4}$.

Las investigaciones sobre colecciones bibliográficas formadas por instituciones de la época nos revelan igualmente esta misma finalidad práctica. Aunque los estudios sobre éstas han sido menos numerosos, ya se pueden contar con trabajos que nos ayudan a desentrañar el potencial intelectual de un determinado grupo social, al emplear estas bibliotecas como instrumento de formación y consulta ${ }^{5}$. La iglesia y la universidad fueron los dos grandes organismos que coparon esta tarea recopilatoria, por tanto, también los estudios, hoy en día, se han centrado en estos grupos. La función docente de las universidades y de los colegios mayores hizo que sus bibliotecas significaran una parte primordial dentro de ellas, ocupando importantes salas de sus edificios y absorbiendo grandes sumas de dinero para su formación y conservación ${ }^{6}$.

A su vez, ya desde la Antigüedad, se venían formando bibliotecas procedentes de organismos eclesiásticos. Catedrales, monasterios y conventos se avituallaban de libros para su uso particular a nivel litúrgico y doctrinal, consiguiendo en el medievo una gran relevancia. A comienzos de la Edad Moderna, éstas, si no pierden importancia, desde luego no sobresalen por su primacía anterior al compararlas, ahora, con el resto de las instituciones más o menos seglares ${ }^{7}$, que reclaman su protagonismo. En estos siglos, la particularidad no radica tanto en la grandiosidad y riqueza de sus ejemplares sino en que cada institución cuenta con su biblioteca propia, creada con el fin de ser soporte intelectual a sus miembros. Por ejemplo, parece que en todas las casas de las nuevas órdenes religiosas: agustinos, dominicos, carmelitas, trinitarios, jerónimos etc. hubo, de mayor o menor tamaño, una librería ${ }^{8}$.

Si la gran mayoría de las instituciones y organismos de la época requerían una colección de libros como apoyo e instrumento de trabajo, era

\footnotetext{
4 Santiago Páez, E., "Las biblictecas del Alcázar en tiempos de los Austrias", El Real Alcázar de Madrid. Madrid 1994, pág. 331.

5 ArIas de SaAvedra, I., "La biblioteca de los jesuitas de Granada en el siglo XVIII. Una aproximación". Actas de la IV Reunión Cientifica de la Asociación Española de Historia Moderna, Alicante, 27-30 de mayo de 1996, vol. I. Alicante 1997, pág. 611

6 Ver por ejempio, la biblioteca de la Universidad de Salamanca durante los siglos $x \vee$ y $x V I$ en REAL DE LA RIVA, C.. "La bitiiioteca de la Universidad de Salamanca". Memoria anual y noticia histórica. Salamanca 1953, pág. 24-29.

7 Marín Martinez, T., “Llas bibliotecas eclesiásticas", en Aloea Vaquero, Q.; Marin Martinez, T. y Vives Gatell, J. (dir.), Diccionario de Historia Eclesiástica de España. Madrid 1972, pág. 259.

8 Ibidem, pág. 261.
} 
lógico que nuestro primer pensamiento fuera que este Índice, con un título tan explícito, tuviera principalmente obras de referencia y consulta del Consejo de la Suprema y General Inquisición. Éste era el órgano supremo y último de todos los demás tribunales inquisitoriales. Coordinaba las líneas de actuación, juzgaba las apelaciones de causas, arbitraba las situaciones de votos discordantes en procesos importantes, etc. ${ }^{9}$. Por tanto, si el propio Consejo se preocupaba del buen ejercicio de sus oficios, así como del correcto dictamen en su decisiones, era imprescindible que contara con un conjunto de obras que proporcionaran la información necesaria a sus miembros.

Por otro lado, generalmente la mayoría de las bibliotecas de los diferentes organismos medievales y modernos se nutrieron de las donaciones particulares que iban recibiendo. El profesor Tomás Marín confirma el nacimiento de las librerías catedralicias, gracias fundamentalmente a la influencia y empuje de sus miembros ${ }^{10}$. Las librerías universitarias tenían en muchas ocasiones este mismo comienzo, el propio cardenal Cisneros, no sólo fue el fundador de la Universidad Complutense, sino también el mayor interesado en crear en ella una gran biblioteca ${ }^{11}$.

Todos los miembros de la Suprema habían pertenecido, de alguna u otra forma, a las mejores universidades de la península, siendo afamados doctores en Derecho o Teología; se les consideraba, sin duda alguna, entre el elevado grupo social de "hombres de letras" y formaban parte, asimismo, de diferentes órdenes religiosas, principalmente dominicos. Reunían, por tanto, los requisitos para que de cualquiera de ellos saliera fácilmente la idea de crear una biblioteca de uso comunal, que sirviera de instrumento al Consejo. Actuando al igual que otros muchos humanistas ${ }^{12}$, cualquier consejero podría haber tomado la iniciativa al donar a esta institución su colección o, por lo menos, parte de ella. Esta actitud, además, requería una inclinación especial a los libros, que no es difícil encontrar en personajes tan relevantes y letrados como los inquisidores generales. Entre todos ellos destaca, en el siglo XVI, el inquisidor general Cisneros, que como hemos visto fundó la gran biblioteca Complutense. Durante el

\footnotetext{
Pérez Villanueva, J. y Escandell. Bonet, B. (dir.), Historia de la Inquisición en España y América, vol. I. Madrid, 1984, pág. 613.

10 Marin Martinez, T., Op. cit., pág. 259

11 Fernandez Férnandez, C., La biblioteca de la Universidad Complutense, Tesis doctoral inédita leida en junio de 2001 en la Facultad de Geografía e Historia de la UCM.

12 Galende Diaz, J.C., "Las bibliotecas de los humanistas y el Renacimiento", Revista General de Información y Documentación, vol. $6, \mathrm{n} .{ }^{\circ} 2,1996$, págs. 91-123.
} 
siglo XVII resalta, sin duda, con estas virtudes la figura del inquisidor general, don Diego de Arce y Reinoso, cuya biblioteca fue famosa ya entre sus contemporáneos ${ }^{13}$ y que además escribió una obra cuyo título confirma todas estas expectativas: De las librerias, de su antigüedad y provecho, de su sitio, de la estimación que de ellas deben hacer las repúblicas $y$ de la obligación que los príncipes, así seglares como eclesiásticos, tienen de fundarlas, augmentarlas y conservarlas.

En el caso de que esta biblioteca hubiera nacido con unos objetivos y circunstancias parecidas a las referidas, la temática bibliográfica debería estar casi monopolizada por el Derecho y la Teología. Y, efectivamente, en el Índice se encuentran obras relativas a estas materias, pero no son precisamente los títulos más habituales y ortodoxos. Resulta extraño que no haga referencia, por ejemplo, a ningún ejemplar de Derecho inquisitorial, tan necesario en la práctica habitual del Consejo. Tampoco se encuentran las obras clásicas y comunes de esta época sobre Derecho canónico y Jurisprudencia, indispensables en una biblioteca con estas características ${ }^{14}$.

En realidad, hasta que no se vio con más minuciosidad el Índice, no nos dimos cuenta de lo que allí se había reunido. Inmediatamente llamaron la atención nombres tan sospechosos como Martin Bucer, Theodore de Bèze, Charles du Moulin..., autores prohibidos de primera clase, heresiarcas. Se encontraban también las obras de Cornelio Jansenio,

13 ANDRES, G. de, "Los manuscritos del Inquisidor General Diego de Arce y Reinoso", Hispania Sacra, XXXIII, 1981, págs. 491-507.

14 De hecho, tras posteriores investigaciones en el AHN (Inq. L. 373, fol. $5 \mathrm{v}$ ), encontramos un catálogo de las alhajas que poseía el Consejo de la Suprema en 1630, y entre ellas cita una docena de libros que estaban conservados con los demás objetos preciosos, en un cajón cerrado con cerradura. Estos debieron formar la pequeña biblioteca que acabamos de describir, pero que no tiene nada que ver con los libros contenidos en el Índice de la Biblioteca Nacional. Los títulos de dichas obras son los siguientes:

"Derecho Canonico, en tres cuerpos de a folio

Derecho Civil, en seis cuerpos corr el indice

Partidas, en quatro cuerpos con el Reportorio

Nueva Recopilacion, en tres cuerpos

Bullario, en quatro cuerpos con el appendix

Fueros del Reyno de Aragon, en dos cuerpos grandes

Commentarios de Bardax, a los fueros de Aragon

Tractatus de officio gubernationis, auctor Ibando de Bardaxi

Repertorium fororum e! onseriantiarum Regni Aragonum

Fori Regni valentie, en un cuerpo grande

Repertori generai y brelie sumari per onde alphabetich de totes les materies de les fuers de Valencia, en quarto

Concilio de Trento, en 8

Directorium inquisitorum». 
varias enciclopedias francesas del siglo XVIII, así como muchas obras anónimas.

Rechazada ya la primera hipótesis, que definía a esta biblioteca como la base intelectual del Consejo en su práctica diaria, cotejé los títulos pertenecientes al siglo $X \mathrm{VI}^{15}$ con el Índice de libros prohibidos del profesor Bujanda ${ }^{16}$. La librería no dejaba lugar a dudas. Era una colección de libros prohibidos que en gran parte de los casos, debían haber sido quemados, y en otros, eran obras cuya lectura no estaba prohibida, salvo algunos pasajes, frases, palabras o nombres que, con el obligado expurgo, podian mantenerse en circulación. A partir de aquí las preguntas se multiplicaban, pero sobre todo, sobresalía una: ¿qué finalidad tenía esta recopilación de libros, que la propia Inquisición se encargaba de condenar, y obligaba a quemar sin dejar rastro de ellos? ¿Tendrían algún cometido específico o esta librería se vino a producir fruto del abandono y desorden que reinaban en el archivo del Consejo?

Para empezar a resolver estas cuestiones, en primer lugar había que cerciorarse de que efectivamente seguían en la Biblioteca Nacional. El hecho de contar con una colección de libros y poder consultarlos físicamente era una oportunidad que no se podía despreciar, y nos daba la posibilidad de saber si todos los ejemplares tenían unas características exteriores afines que indicaran un dueño común. Puesto que el número de títulos que integraban la biblioteca era muy elevado, se ha hecho para este artículo una selección, escogiendo los libros pertenecientes al siglo $X V I$, que suman en total 223 , dejando el resto de la librería para la Tesis Doctoral y próximas publicaciones.

Tras una ardua labor de identificación, he podido consultar en la $\mathrm{Bi}$ blioteca Nacional, 212 ejemplares. La mayoría tienen una encuadernación vulgar, en pergamino de color claro, de poca calidad, que sirve de cubierta a una fina tapa de pasta, con dos cuerdas de cuero para cerrar el libro.

Contrariamente a la lógica y costumbre general de poner el nombre del dueño de alguna manera u otra, el Consejo no puso en ningún momento signo, ex libris o marca que lo identificara, debido seguramente al desprecio que sentía el propio Consejo hacia libros tan peligrosos.

\footnotetext{
15 Agradezco a la profesora Elisa Ruiz García las sugerencias y ánimos que me dio para iniciar este camino.

16 Bujanda, J.M., Index de'l Inquisition espagnole 1583, 1584 par J.M. de Bujanda; avec l'assistence de René Davignon, Ella Stanek, Marcella Richter. Sherbrooke 1993.

17 En estos casos, transcribo íntegramente la ficha del Índice original de la BN.
} 
En cambio, más del $60 \%$ cuentan con varias signaturas colocadas en diferentes lugares, dependiendo del orden en que se clasificaron los libros. La más interesante es la dispuesta en el lomo de los libros. Consiste en un trozo de papel, de $15 \times 10 \mathrm{mms}$ aproximadamente, colocado en el tejuelo con dos signaturas con números de 3 o 4 dígitos. Una está tachada, y la otra aparece arbitrariamente escrita en cualquier espacio libre del pequeño papel. Hoy por hoy, no se puede asegurar el orden que expresan hasta que no se vean todos los ejemplares con su signatura.

En la tapa aparece escrito, en tinta muy clara la letra inicial del apellido o de la primera palabra del título por el que se ha ordenado. Ésta, sin duda, pertenece a la clasificación realizada por el bibliotecario que hizo el Índice, además el tipo de la letra es del siglo XIX. También en la contratapa final suelen encontrarse dos números, uno arriba y otro más abajo. El primero va siempre precedido de " $n .^{\circ}$ " y es mayor que el de abajo, que generalmente solo consta de una cifra. Ambos parecen trazados por la misma mano. Tampoco, en la actualidad, podemos responder al orden que expresan.

Pero no todos los libros tienen estas características; hay ocho que no he podido identificar sus títulos ${ }^{17}$. Algunas obras se han podido reconocer, pero no coincide la fecha, con la del ejemplar conservado en la Biblioteca Nacional, o se han identificado, pero sólo existen ejemplares en otras bibliotecas. También se han encontrado, obras que identificadas y coincidentes con el Índice, no parecen haber pertenecido al Consejo porque tienen el sello de la Biblioteca Real, lo que resulta extraño, pues no parece probable que los llevaran allí antes del Ministerio de Fomento y, en el caso de que así hubiera sido, el sello deberían llevarlo todos.

El fuego era uno de los sistemas más eficaces de erradicar la herejía. El Santo Oficio, consciente de que las ideas heréticas se transmitian principalmente a través de la producción libraria, quemaba los libros prohibidos en medio de un ritual pedagógico, donde el pueblo participaba como espectador. Pero existen noticias de que no todos los libros tenían este mismo fin; había algunos que milagrosamente se salvaban: "Que todos los libros prohibidos que se contienen en el memorial que se mando despachar se recojan y los que fueren de authores hereticos sean quemados pubilcamente en el auto y de los demas se pongan en alguna pieça de la inquisicion a buen recado" ${ }^{18}$. Esta pieza albergaba una biblioteca de libros prohibidos, siempre y cuando éstos no fueran de autores heresiarcas. De

18 AHN, Inq., leg. 4517, caja 2. 
hecho, todos los tribunales tenían obligación de tener y cuidar esta biblioteca, cuya finalidad, según Virgilio Pinto, era ufacilitar la labor de control sobre los libros existentes en el mercado y la elaboración de índices o catálogos» 19 .

Henry Lea describe brevemente la biblioteca de libros prohibidos que tenia la Inquisición de Valencia. Su estado de conservación revelaba un completo olvido, habiéndose robado muchos de ellos, mientras el resto, que permanecían afinados en una sala, se encontraban a merced de los gusanos ${ }^{20}$. Asimismo, en un auto del Consejo se mencionan los graves descuidos a los que eran sometidas estas obras, por parte de los tribunales, provocando que los oficiales del Santo Oficio los cogieran y leyeran sin licencia alguna.

La biblioteca del Consejo podría tener este mismo origen y una función similar. Pero la Suprema conservó en su librería muchas obras de autores herejes, cuyo fin era morir quemados y además, a juzgar por el estado de conservación de los ejemplares de la Biblioteca Nacional, el Consejo puso mucho esmero en su custodia, guarda y clasificación. En general, todos están bien conservados, sin agujeros, humedades ni otros deterioros físicos y la mayoría fueron ordenados de una forma $u$ otra, pues disponen de su correspondiente signatura. Pero esto nos lleva de nuevo, a preguntarnos: ¿qué utílidad tenía el esfuerzo que suponía guardarlos, ordenarlos y ejercer un cierto control sobre ellos, si su conservación fomentaba el peligro de que alguien los leyera y poseyera sin autorización?

Esta cuestión nos lleva a conocer a quiénes necesitaban hacer uso de estos libros: la Junta de Calificación. Formada por varios calificadores (eruditos expertos sobre todo en Teología y Derecho pero también especialistas en otras materias), que se reunian para decidir qué libros se prohibian, qué párrafos o frases debían ser expurgados y cuáles obras estaban libres de toda herejía. Su objetivo estaba fundamentalmente enfocado a la calificación de libros de nueva edición, pero su misión principal era elaborar los índices o catálogos de libros prohibidos, en donde, de nuevo en muchas ocasiones, se volvian a corregir obras que ya estaban calificadas, aprobando o desaprobando decisiones anteriores ${ }^{21}$. Cada dictamen lleva-

19 Pinio Crespo, V., Inquisición y control ideológico en la España del siglo xvi. Madrid 1983, pág. 62.

LEA, H., Historia de la Inquisición española. vol. III. Madrid 1983, pág. 318.

21 Siera Corflla, A., La cerisura en España. Indices y calálogos de libros prohibidos. Ma. drid,1947, págs. 139-143. 
ba consigo la lectura de la obra por uno o varios de los calificadores. En todo caso, su parecer debía ser luego corroborado por el Consejo de la Suprema Inquisición ${ }^{22}$. Teniendo en cuenta que durante el siglo xVl, la producción libraria fue en aumento en todos los países europeos, la cantidad de ejemplares (antiguos y nuevos), que consultaron durante estas Juntas, debió ser inmensa ${ }^{23}$.

Unido al elevado número de libros que debian inspeccionar concienzudamente, se encontraba el problema de hallar los libros en sí. Las obras tradicionalmente heréticas eran difíciles de localizar, pues a lo largo del tiempo se fueron quemando y destruyendo, haciendo que la propia Suprema tuviera problemas para consultarlos: «Recurriendo los papeles de materias de calificaciones, he hallado que no ha podido tomar el Consejo resolucion sobre diferentes delaciones, hechas la maior parte por Vuestra Reverendísima, por falta de los libros delatados... se sirva buscar estos libros y remitirlos al Consejo con toda breuedad y para que en adelante no se tope en este inconveniente, manda el Consejo que Vuestra Reverendísima, con las delaciones que hiziere, embie siempre los libros delatados" ${ }^{24}$.

Cuando la Junta se reunia para elaborar un nuevo catálogo, se sufrían las mismas dificultades. En una nota para la Jurita de Calificación en 1611,

22 AHN, Inq., leg. 4.519, exp. 8. Un ejemplo del modo de actuar de esta Junta, se puede observar en este auto: "En la villa de Madrid a veinte y siete dias del mes de setiembre de mil y seiscientos y zinquenta y ocho años, el señor don Juan Santos de San Pedro, del Consejo de su Magestad de la Santa General Inquisicion en virtud de su comission estando en Junta y vista de negocios con los padres maestros el abbad de Santa Anastasia, fr. Alonso de Herrera del orden de los minimos de san Francisco de Paula, fr. Alonso Perez de la de San Bernardo, Geronimo de Salzedo de los clerigos menores, fr. Bernardo de Ontiberos de la de San Benito, fr. Antonio de Rivera de la de San Francisco, todos calificadores del dicho Consejo. Viose en dicha junta vna parte de los fragmentos de vn libro cuyo titulo es... y hauiendo conferido largamente sobre los dichos elogios y demas versos y prosa en ella contenidos dixeron conformes que el dicho libro es vna protestacion del judaysmo con toda la peruersidad que se puede pensar en ymitacion de los que los hereges luteranos y caluinistas han hecho en kalendarios publicos que han hecho poniendo por martires los herejes que an sido castigaóos por el Santo Officio en España y Roma y asi ahora quieren los judios formar martirologio de los castigados por el Santo Officio y asi considernado que esta impresso en lengua castellana y que podra haver otras copias conviene se prohiba luego cin totum" por edictos por hauer en el heregias $y$ apostasias contra la fee catholica y preuenir en los puertos se tenga summo cuidado para que no entren en España por los grandes daños que dello se pueden seguir y lo firmaron.

(En el margen izquierdo superior, la respuesta del Consejo) En Madrid 9 de octubre 1658. Como pareze a los calificadores se recoja y prohiba. Escriuase a los comisarios de los puertos esten con cuidado en las vissitas. Su Señoria llustrisima, Señores Bravo. Santo, Sotomayor (rúbrica del secretario)"

23 Sierra Corella, A: Op. cit., pág. 120. Tres años duró la Junta para el índice expurgatorio de 1612 , debido a la cantidad de libros a revisar por los calificadores.

${ }^{24}$ AHN, Inq., leg. 4.470 , carp. 30. 
se denuncia este problema como causa principal de ciertos errores contenidos en el catálogo anterior: «...que por falta de libros y no se hallan o no saber donde estarian, se dexaron la vez passada muchos, puestos en el catalogo con su estrellica por expurgados, sin hazer la expurgacion ni mencion aca dellos en el expurgatorio y otros, por la misma falta de libros, absolutamente se vedaron» ${ }^{25}$.

Las obras impresas en el extranjero también daban muchos problemas. Constituían uno de los principales objetivos de la Junta de Calificación, pues de fuera de las fronteras era de donde venía la verdadera infección herética transmitida por medio de los libros. Desde mediados del siglo XVI, la circulación de libros entre Europa y la Península se fue haciendo cada vez más débil, debido precisamente a la eficaz censura inquisitorial impuesta en las fronteras y puertos norteños, así como a través de las constantes visitas a los libreros y comerciantes de libros. Por este motivo, la cantidad de obras extranjeras que llegaba a España fue en ocasiones tan escasa, que a los propios calificadores les resultaba difícil y fatigoso localizarlas.

Las soluciones del Consejo para estos inconvenientes son variadas. En primer lugar, la Suprema puso a todas las Inquisiciones a buscar los libros deseados, pidiéndoles continuamente que se les remitiesen ciertos libros sospechosos o prohibidos: "a los inquisidores de Murcia que se recibieron las balas de libros y en siendo nueua impresion los remitan al Consejo" ${ }^{26}$; "a los inquisidores de Valladolid que hagan nueua diligencia en buscar el libro Hipoteposeon y le embien al Consejo "27. Tan complicado era a veces hallar un libro extranjero que los comisarios, encargados de encontrarlos, tenían licencia para que, si no daban con él, lo pidiesen a alguna librería del extranjero ${ }^{28}$.

Las vías de avituallamiento de ejemplares eran las visitas a librerías particulares o de libreros, las propias bibliotecas de libros prohibidos de los pequeños tribunales ${ }^{29}$ o las confiscaciones de valijas y balas de libros que se dirigían o venían del extranjero ${ }^{30}$. También era usual recurrir a otras bi-

5 AHN, Inq., L. 4.517, caja 2, s.f.

AHN, Inq., L. 1.232 , fol. 19.

AHN, Inq., L. 1.232, fol. 8.

AHN, Inq., L. 4.471, exp. 24.

AHN, Inq., L. 1.265, fol. 394: “...para obiar estos daños se pondra mucho cuydado y custodia asi en los libros que ay estan recojidos en el secreto como en los que de nuevo se fueren trayendo al Santo Oficio para que el dia que el Consejo los pidiere se puedan remitir".

30 A.HN. inq., L. 1.232, fol. 20: "a los comisarios de Bilbao, San Sebastian y otros que embien vnas caxas de libros". 
bliotecas que tuvieran licencia de libros prohibidos y a las que los calificadores podrían acceder si tenían la suerte de encontrar las obras deseadas. Esto podía traer sus dificultades o, por lo menos, exigía tener ciertas dependencias hacia las demás instituciones, obligando en ocasiones a la Suprema a imponer la primacia de las labores de calificador frente a las reglas de cada organismo ${ }^{31}$.

Importante debió ser el apoyo que, a este respecto, ofreció la biblioteca de libros prohibidos conservada en el monasterio de El Escorial. Ésta tenía autorización de la Suprema, siempre y cuando esta clase de libros se guardaran en una pieza aparte con cerradura propia y poniéndoles una advertencia. De hecho, dicha licencia fue concedida por el Consejo, porque el Inquisidor General y el Consejo de la Santa General Inquisición, "la tienen alli para poderse seruir de qualquiera libro della que aya menester" ${ }^{32}$. De esta forma, la Suprema determinaba el orden en que habían de estar guardados los libros y aprovechaba la sala para enviar alli otros libros prohibidos ${ }^{33}$, creando así una librería perfectamente segura, sin problemas de consulta, bastante completa y para uso casi exclusivo del Consejo. Una pequeña prueba de que varios libros de esta biblioteca se emplearon para la elaboración del Catálogo de 1612, es la cita de la "memoria de los libros que se traxeron de San Lorenzo para el Catalogo" en un índice de libros,

${ }^{31}$ AHN, Inq., L. 373 , fol. 47 : “... por quanto se nos a hecho relaçion que con ocasión del mandato general que a salido de que los religiosos de Sant Francisco no tengan en sus çeldas libros particulares se quita a los padres, que son calificadores del Sancto Officio de la inquisicion, los libros que tienen en sus celdas y estudios y que no los pueder lleuar a otros conuentos donde fueren mudados. De lo qual resulta impedimento al Santo Officio porque sin tener presentes los libros no podran estudiar y dar las çensuras tan açertadamente como conuiene a la verdad con que se han de juzgar las causas de fee y a la misma religion de Sant Françisco y a su autoridad conuiene tener calificadores en la inquisicon y que esios sean doctos y de entera satisfaçion. Por ende por la autoridad apostolica de que en esta parte usamos, exortamos y, en virtud de santa obediençia, mandamos a los superiores de la dicha religion no quiten ni saquen de las çeldas de los padres calificadores del Santo Officio de la dicha orden los libros que tuuieren ni les impidan el usso dellas en sus celdas y los que han sacado, se los bueluan, dexando en quanto a la propiedad de los tales libros y a la enagenaçion dellos en su fuerça y vigor la regla y obseruançia que profesan de la pobreça...".

32 AHN, Inq., L. 291, fol. 405

33 AHN, Inq., L. 291, fol. 405: "Se hagan dos hindiçes el vno para que lo tenga el dicho Consejo y el otro quede con los dichos libros y supuesto que a de estar con el dicho titulo enviaremos a juntar con ellos los libros pronividos que ara tubieremos y los que de aqui adelante se fueren avmentando". Lo cual, efectivamente efectuaron puesto que el secretario Huerta confirma que salieron de su oficio cerca de 800 cuerpos "sin impresiones enteras", para guardarse en la libreria de San Lorenzo el Real, además de otros 32 ejemplares de libros arábigos y de Granada (AHN, Inq., L. 1.273, fol. 123). 
papeles, censuras y calificaciones del secretario empleados por la Junta ${ }^{34}$.

Quizá una cuestión tan sencilla, como la distancia que separaba al Consejo, instalado en la Corte, del monasterio de El Escorial (sobre lo que, ya desde su fundación, hubo quejas ${ }^{35}$ ) pueda ser la razón de que la escasez libraria, que venía sufriendo la Junta durante la elaboración del Catálogo de 1632, no fuera, con esta biblioteca ni con las otras soluciones, en absoluto resuelta. En realidad, parece que a raiz de este hecho, salió la propuesta que se hizo al Consejo de formar una librería con toda clase de libros prohibidos, que sirvieran de consulta y apoyo del propio Consejo y de sus calificadores. No tenemos la propuesta original pero ésta se presentó ante la Suprema por la persona encargada de la organización de los papeles, libros y temas administrativos de la Junta el secretario del Consejo para la Corona de Aragón, el licenciado Sebastián de Huerta. Varios consejeros, que estuvieron allí presentes, votaron a favor de este proyecto, seguramente, porque ellos mismos estuvieron en la Junta de Calificación anterior y sufrieron los problemas de insuficiencia bibliográfica. Aprobado el proyecto, se estableció que la librería se colocaría en las habitaciones de la secretaría de Huerta, quedando el cuidado a su cargo ${ }^{36}$.

Quien relata todo esto es el sucesor de Huerta, Juan de Clavijo, secretario asimismo a la muerte del primero, y que continúa dándonos detalles de los comienzos de esta librería. La primera partida se conformó con un gran lote de libros que ya se conservaban en la secretaría de Aragón. En un principio, se almacenaban en casa de don Pedro Pacheco, presidente de la comisión de calificadores y encargado de organizar todas las actividades relativas a la censura bibliográfica. Producto de esta labor y la de sus antecesores en el cargo fue la acumulación en su casa de libros prohibidos, al no poderlos devolver a sus dueños, ya que la mayoría de las veces no constaban de dónde o de quién procedían. Coincidiendo con el nuevo edificio que el Consejo adquirió en Madrid, y que supuso el fin de la vida errante de los papeles y libros, Pacheco llevó a la secretaría de Aragón dichos libros, junto con los estantes de madera en que estaban colocados. Comenta Clavijo que el Consejo mandó quemar todos los duplicados y papeles sueltos de este lote, lo que coincide con un auto del Consejo de 1632 ordenando lo mismo ${ }^{37}$.

34 AHN, Inq., L. 4.519, exp. 8.

35 Bouza Álvarez, F.: Op. cit., pág. 94.

36 AHN, L. 4.470, carp. 30.

37 AHN, Inq., L. 373, fol. 207. 
Una segunda partida de libros de esta librería la componían aquéllos conservados en el convento de Nuestra Señora de Atocha. Aquí se guardaban gran parte de los papeles de la secretaría mientras la Suprema permaneciera en Madrid sin sede fija. Una vez que el Consejo se estableció definitivamente, el archivo entero se traspasó al nuevo edificio. En la mudanza se encontraron varios libros "que deuieron ser resulta del expurgatorio del año de $612{ }^{38}$ y se integraron a la nueva librería.

Pero el plan no se quedó aquí, era más ambicioso. Se proyectó que los libros prohibidos que el Consejo no tenía aún se los enviaran desde las demás Inquisiciones. Para ello, se ordenó a todos los tribunales, que mandaran una relación de todas las obras conservadas en sus librerías. Las inquisiciones contestaron prácticamente todas ${ }^{39}$, pero el proyecto no siguió adelante, según Clavijo: "porque la obra es de special trauajo y pide conocimiento y studio de los Catalogos y noticias de los autores y sus titulos que, añadiendose a trauajo y ocupacion tan continua, ninguno de los que fueron de parecer se formase la librería quiso para si el trauajo de formarla y sin duda huuieran tomado sobre si este trauajo los padres Juan de Pineda y Diego de Alarcon, de la Compañía de Jesus que reconocieron la importancia della quando se formo el expurgatorio del año de 632» 40 .

No obstante, a pesar de ello, la nueva librería siguió ampliándose. La Suprema continuó pidiendo los libros a sus comisarios a medida que iba necesitándolos o cuando sabía que venían nuevos del extranjero. Cuando el Consejo decidía que el libro quedaba prohibido, se reservaba un ejemplar para su librería si no tenían allí ninguno ${ }^{41}$. De hecho, la cantidad de libros que ingresaron a partir de la formación de la librería hizo que poco después se ordenara la creación de un libro registro en el que se hiciera memoria de ellos, figurando además la razón por la que estaban prohibidos. Este inventario no se ha encontrado, pero en los libros que se conservan en la Biblioteca Nacional aparece en la portada la cita del Catálogo que los prohibió o borrado el nombre del autor y puesto en su lugar "Authore damnato", o directamente "Damnatus omnime». Los que recibían su

38 AHN, Inq., leg. 4.470 , exp. 30 .

39 Las contestaciones se conservan en AHN, Inq., leg. 4.517; carp. 1.

40 AHN, Inq., leg. 4.470 , carp. 30.

41 AHN, Inq., leg. 4.470, carp. 30. "el (libro) prohiuido es Joannes Vverden Haegen al qual Vuestra Alteza en el expurgatorio le prohiue omnino, como consta del folio 561 ... por vsar este autor communmente de voces peregririas, por llamar siempre a Dios con nombre de Jehoba a lo moysaico y estar todo el libro inserto de frazes supersticiossas y iusitadas en la pureza de nuestra fee por lo qual remito a Vuestra Alteza este libro para que mande que se retire en el secreto de este real Consejo... a 11 de jullio de 1645". 
correspondiente expurgación, teóricamente debían ser devueltos a sus dueños, lo cual, como ya se ha visto, no siempre ocurría por no saber en muchas ocasiones a quién pertenecían. Ahora, en el inventario, también se debía hacer constancia del nombre del dueño y la fecha en que era devuelto el libro.

Puesto que la librería nueva del Consejo tenía razones primordialmente prácticas para haber nacido, siendo objeto de consulta y cotejo para la Junta y no se caracterizaba precisamente como sus contemporáneas, por su finalidad humanista como foco privilegiado y difusor del conocimiento ${ }^{42}$, tampoco después seguiría los derroteros habituales de sus homólogas. Éstas, a partir de la segunda mitad del siglo XVI, comienzan a cerrarse en sí mismas sin que entre sus funciones principales esté el acercamiento de los libros al público; el préstamo se convierte en una actividad extraña y los libros de las bibliotecas, incluidas las universitarias, se encadenaban a los estantes. En cambio, el particular conjunto librario guardado escrupulosamente en el Consejo de nuevo se sale de la norma. A mediados del siglo XVII se establece un sistema de préstamo, surgido a partir de los continuos desacatos que venía sufriendo la librería, y de los que se queja el secretario Clavijo, que los tiene en su custodia: "(la librería)... pudiera estar mas adelante en numero de los libros a no hauer desayudado la curiosidad de algunos señores del que con pretexto de negocio o de la licencia de poderlos leer y tenerse an quedado con ellos ${ }^{43}$. Debido a lo cual en 1548 se provee que «si alguno de los señores de este Consejo pidiere algun libro se le de, dexando reciuo de el y firmado de su mano en el dicho libro para que con el se le pueda pedir le buelua quando conuiniere" ${ }^{44}$.

Un sigio después de su creación, la biblioteca de la Suprema mantenía el mismo sistema de préstamo. Se mandaba una carta al Consejo pidiendo el libro, expresando quién y para qué lo solicitaba: «Muy Poderoso Señor. Joseph Cassani de la Compañía de Jesus, calificador del Consejo, dice que esta trabajando una obrita del servicio de Dios y defensa de la Iglesia por ser en materia dogmatica e impugnacion del Jansenismo, para lo que necesita ver en su fuente algunas propuestas del libro de Cornelio Jansenio y, aunque tiene lizencia del Excelentisimo Señor Cardenal Inquisidor General para leerle, no le halla por estar prohibido. Por lo qual a

\footnotetext{
42 Bouza Alvarez, F., "La biblioteca de El Escorial y el orden de los saberes en el siglo XVi", El Escorial: Arte, poder y cultura en la corte de Felipe II. El Escorial, 1988, pág. 93.

43 AHN, Inq., leg. 4.470, exp. 30.

44 AHN, Inq., leg. 4.470 , exp. 30 .
} 
Vuestra Alteza suplica se sirva concederle se le de uno de dichos libros de los de la librería de libros prohibidos por el espacio de seis meses con obligacion de restituirle en que recibiera merced. Joseph Cassani» ${ }^{45}$. EI Consejo ordenaba que se le entregase el libro pedido por el tiempo sugerido, pero dejando antes un recibo: "(Cruz) Reciví las obras de Cornelio Jansenio en diez tomos de la librería de libros prohibidos por seis meses y por ser verdad lo firme en Madrid a 18 dias de abril de 1714. Joseph Cassani» ${ }^{46}$.

El aumento de la librería no parece que decayera en el siglo XVIII. Los libros debieron ser tan numerosos que provocaban graves problemas de espacio. Se sabe que no sólo ocupaban parte del archivo de la secretaría de Aragón, como se dispuso en un principio, sino que también se llevaron a las bóvedas del edificio del Consejo. Por ello, la Suprema ordenó que se hiciera de nuevo una revisión de los ejemplares que hubiera duplicados para poderlos quemar y hacer sitio a otros ${ }^{47}$.

Como se ha visto, la utilidad de esta colección bibliográfica estaba muy lejana del objetivo común de aumentar o difundir conocimientos, procurando con ello el desarrollo intelectual de sus lectores. Sin embargo, se puede decir que al igual que otras bibliotecas ${ }^{48}$, ésta facilitaba a sus usuarios (calificadores y consejeros) una gran capacidad de actuación, apoyando sus dictámenes en las fuentes mismas a la hora de determinar o evaluar una herejía.

No pretendía en modo alguno la biblioteca del Consejo representar la riqueza y poder del organismo poseedor con ediciones lujosas y caras. El mero hecho de su condición hereje hacía que los libros carecieran de valor a los ojos de los inquisidores, e incluso, que sintieran un gran desprecio por ellos. A pesar de ello, la necesidad acuciante de proteger el catolicismo frente a las ideas heréticas hizo que la Suprema reconociera la conveniencia y utilidad de esta recopilación libraria, por encima de cualquier peligro y de su propia repulsa.

La tipología libraria encaja perfectamente con la esencia de los libros descritos. De los 223 libros que se conservan dei siglo XVI, muchos de los cuales fueron recogidos en el siglo XVII, son todos impresos menos uno. De ellos sólo siete han sido impresos en España, con la ciudad universi-

\footnotetext{
$45 \quad$ AHN, Inq., leg. 4.517, exp. 1.

46 AHN, Inq., leg. 4.517, exp. 1.

47 AHN, Inq., L. 373 , tol. 316 .

48 Bouza Álvarez, F., Op. cit., pág. 94.
} 
taria de Salamanca en cabeza. El resto de los libros han salido de imprentas de países extranjeros. Los lugares de impresión coinciden con las regiones de mayor movimiento hereje. Ciertas ciudades, como Ginebra y Basilea, que eran en ese momento los grandes centros tradicionales de editoriales protestantes ${ }^{49}$, cuentan con quince y trece obras respectivamente en la biblioteca del Consejo. Alemania, otro de los grandes productores de libros e ideas heréticas, presenta muchas ciudades como lugares de edición en las obras del índice: trece están editadas en Colonia, doce en Frankfurt, más otras en diferentes ciudades alemanas, como Wittenberg, donde se estableció Lutero a principios del siglo XVI.

Los libros que procedian de los epicentros protestantes, sobretodo de Ginebra, provocaban terror en el mundo católico, por lo que era muy difícil venderlos fuera de los países reformistas. Para introducirlos, se hacían ediciones subrepticias o clandestinas, "omitiendo el lugar de impresión, el impresor y hasta el nombre del autor y dando lugares, años y nombres de autores imaginarios y absurdos» ${ }^{50}$. En el índice aparecen quince obras sin lugar de impresión y otras tantas sin autor, las cuales, ya por la sospechosa ausencia de uno de estos datos, quedaban prohibidas por el Santo Oficio.

El jesuita padre Gretser, especialista en bibliografía prohibida de su tiempo, escribió dos listas con nombres de tipografías sospechosas para la Junta de Calificadores de 1612, con el fin de orientarles sobre los libros que, aunque por sus autores o texto pudieran ser dignos de confianza, su lugar de edición ya les indicarían peligro (incluso aunque pertenecieran a ciudades católicas) ${ }^{51}$. Advierte, por ejemplo, que los tipógrafos de Ginebra en vez de incluir en la impresión el lugar verdadero, acostumbraban a poner el nombre de "Lugduni», intentando así introducirlos en países católicos. De la misma forma actuaban los holandeses utilizando el lugar de "Lugduni Batavi» en sus libros ${ }^{52}$. Por lo tanto, cualquier lugar de edición que coincidiera con algún nombre de las listas dadas por el jesuita tendría muchas posibilidades de ser censurada por la Junta. Justamente las obras publicadas en «Lugduni» son las más numerosas de la biblioteca del Consejo ( 34 obras), así como también se incluyen otros ejemplares cuya edi-

49 ClaiR, C., Historia de la imprenta en Europa. Madrid, 1998, pág. 241.

50 MARTiN, H.-J., cLa circulación del libro en Europa y el papel de Paris en la primera mitad del sigio XVII", en PETRucci, A., Libros, editores y público en la Europa Moderna. Valencia, 1990, pág. 159.

Sierra Corella, A., Op. cit., pág. 122-124.

lbídem, pág. 124. 
ción coincide con las listas de nombres sospechosos. Ediciones por tanto, que según Gretser, serían clandestinas o furtivas.

A su vez, la Junta de Calificación recopiló, para su labor, un elevado número de libros impresos en Italia, especialmente en Venecia (uno de los centros principales de la industria libraria en el siglo XVI), varios de ellos impresos por el afamado impresor, Aldo Manucio. Del resto de las ciudades mencionadas destacan en esta biblioteca los nombres de casi todos los impresores más conocidos de la época: Johan Oporin de la ciudad de Basilea, Jean Le Preux y Eustace Vignon ambos de Ginebra, Birckman y Gymnich de Colonia, Sigmund Feyerabend de Francfurt, Cristóbal Plantino en Amberes, etc.

Si comparamos la biblioteca del Consejo con las librerías de los grandes libreros de Amsterdam en el siglo XVII, se observa que curiosamente los lugares de edición de las obras de ambos son prácticamente los mismos. Según Henri-Jean Martin, en los catálogos de libros holandeses apenas se encuentran libros impresos en España, en cambio, poseen muchos publicados en Alemania y en segundo lugar en Francia y Suiza, sobre todo Ginebra ${ }^{53}$.

El idioma de las publicaciones es mayoritariamente el latín, como la generalidad de los libros publicados hasta principios del siglo XVII. Siendo también en esta lengua las anotaciones, avisos o prohibiciones escritas a mano por los calificadores. El siguiente idioma más empleado en estas obras es el italiano.

En cuanto a las materias de los libros, observamos una gran variedad. La Inquisición puso especial énfasis en censurar los libros de contenido teológicointelectual y espiritual, así como se especializó en prohibir toda clase de Biblias en lenguas vulgares o ediciones extranjeras en latín, relativas al Nuevo Testamento ${ }^{54}$. Los inquisidores pensaban que las traducciones de la Biblia fomentaban la aparición de interpretaciones que se alejaban de las canónicas y oficiales ${ }^{55}$. Pero el control ideológico no se ciñó únicamente a esta clase de textos. La explosión de ediciones de autores clásicos que vivió el siglo xvi fue también objeto de persecución por parte del catolicismo porque, según el Padre Getser, «imprimen además los Santos Padres griegos y latinos, pero rarísimamente sin veneno, que derraman ya en las epístolas dedicatorias, ya en

\footnotetext{
53 Martín, H.-J, Op. cit. pág. 143.

54 AlCAlÁ, A., Literatura y Ciencia ante la Inquisición española. Madrid 2001, pág. 67-70.

55 Gimeno BLAY, F., “Quemar libros... ¡Qué extraño placer!», Seminari Internacional d'Estudis sobre la Cultura Escrita. Universitat de València. Valencia 2001, pág. 15.
} 
los nuevos prefacios, o en los escolios, o en las tablas, si no es en la misma transcripción. Por obtener lucro imprimen también estos tipógrafos, sobre todo los de Francfort, las obras de autores católicos, jurisconsultos, como Covarrubias y otros doctores españoles e italianos, filósofos, médicos, filólogos, etc. aunque de intento o de pasada hablen contra las herejías, lo cual no se debía consentir, a no constar de la sinceridad de impresores" ${ }^{56}$. Como se observa, la prohibición y sobre todo el expurgo abarcaron todas las ciencias y las artes que utilizaban el sistema librario para expresarse. En consecuencia, las obras de Teología y Doctrina religiosa sobresalen en número en el Índice, pero también aparecen en esta biblioteca obras referentes a otras disciplinas: Derecho, Historia, Medicina, Matemáticas, Astronomía o Literatura...

Si uno de los mayores «logros" de la Inquisición fue la masiva destrucción de libros de contenido, sentido o influencia herética, de tal forma que de algunos de ellos sólo han quedado muestras francamente reducidas ${ }^{57}$; por otra parte, el Consejo de la Inquisición ha dejado como herencia aquellos libros de los que precisamente se quiso privar a la sociedad. De hecho, esta colección bibliográfica posee muchas obras de gran difusión social y que se conservan en diversas bibliotecas europeas y españolas, pero también ha constituido para la Biblioteca Nacional la incorporación de un amplio repertorio de obras prohibidas o expurgadas, que en muchas ocasiones significan el único ejemplar conservado en la Península lbérica ${ }^{58}$.

Es además importante este repertorio porque en muchos de estos libros se refleja claramente la actividad de los calificadores, con sus característicos expurgos o tachones de palabras y frases ${ }^{59}$, asi como censuras, pensamientos o dudas, que emergían tras la lectura del texto y sus conclusiones finales, accesibles gracias a su escritura en los margenes de los libros ${ }^{60}$. En otros de estos libros han sido los propios lectores quienes han plasmado su interés y conocimientos en las notas marginales ${ }^{61}$.

\footnotetext{
56 Sierra Corella, A., Op. cit., pág. 121-122.

57 En Valencia, tan sólo se conservan el Salterio y algunos manuscritos de Biblias, como resultado del edicto del Inquisidor Juan de Monasterio de 1498, mandando quemar todas las Biblias, manuscritas o impresas, redactadas en lengua vulgar. VentuRA, J., La Biblia valenciana. Barcelona 1993.

58 Según el Catálogo Colectivo del Patrimonio Bibliográfico Español.

54 Pot ejemplo, en CASO, I.. Sphaera civitatis hoc est, res publicae recte ac pie secundum leges administrandae ratio... Francofurti 1593.

60 Como en el caso de la nota marginal que aparece en la portada del libro de ARIAS MONTANo, B., Commentaria in duodecim prophetas... Antuerpiae 1583: "caute lege quae hic dicuntur de non condemantis antiquis tilosophis moralibus".

61 A saber, CElso, C.A., De re medica. Libri VIII item Q. Sereni liber de Medicina. Patavii 1563.
} 
En el catálogo, que incluyo a continuación, se exponen las obras por orden alfabético de autor, por tanto, las obras anónimas son las primeras. El nombre y apellidos del autor se expresan en negrita, latinizados en los casos en que el ejemplar esté escrito en esta lengua. Los autores en lenguas romances, aparecen con el nombre vulgarizado. A continuación, en cursiva, se presenta el título de la obra, tal cual se encuentra en cada ejemplar, por ello, en muchas ocasiones se incluye de nuevo el nombre del autor dentro del título, como se acostumbraba en esta época. No he querido omitirlo porque en el Índice de la Biblioteca Nacional, en muchas ocasiones, aparece el título de esta forma, lo cual ha significado para mí una pista a la hora de identificarlos. A continuación, se encuentra el año y lugar de edición (el último no aparece en el Índice original) y, al final de cada ficha, la signatura de la Biblioteca Nacional. En ocasiones se añade más de una signatura, porque existen dudas sobre cuál de los ejemplares perteneció al Consejo al no llevar ningún tipo de signo.

No transcribimos aquí el Índice original de la Biblioteca Nacional por no hacer el trabajo demasiado extenso y sobre todo, porque en este caso, carece de utilidad. Sólo en aquellas obras no identificadas, añadimos la ficha según este Índice.

\section{CATÁLOGO DE LA BIBLIOTECA DEL CONSEJO DE LA SUPREMA INQUISICIÓN (1500-1599)}

1. Canones et Decretales oecvmenici et generalis Concilii Tridentini..., 1565; BN: $3 / 6459^{62}$.

2. Canones Mediorum seu aequabilium motuum atque aequationum, 1585, Venetia; no encontrado en $\mathrm{BN}^{63}$.

3. Christianus crucius, vita Jesuchristi etc, 1578; no encontrado en BN.

4. Codicis domini Justiniani sacratissimi principis libri nouem cum vetustis exemplaribus tum scriptis tum impressis diligenter collati, et in antiquam eleganitam, sermonisque munditiem, propulsatis errorum nebulis..., $1538^{64}$, Parisiis; BN ${ }^{65}$.

\footnotetext{
62 En el Índice aparece la íecha de edición 1545.

63 Únicamente he encontiado un ejemplar con este título, conservado en la biblioteca del monasterio de la Vid.

64 En el Índice aparece la fecha de edición 1533.

65 Existen en la BN más de una docena de ejemplares con estas características, sin que ninguno tenga señales de haber pertenecido a la biblioteca del Consejo.
} 
5. Commentaria in quatuor Prophetae Isaias, Jeremias, Baruch, Exechie (lesaiae Prophetae) vetus et noua ex hebraico versio, cum commentario... vulgatus interpres a plurimorum calumniis vindicatur..., 1567 ${ }^{66}$, Antuerpiae; BN: 5/12294; 3/67954.

6. Commonefactio cuiusdam theologi de sacra Domini coena. et eiusdem commonefactionis consideratio scripta a quibusdam veritatis \& concordiae amantibus theologis, 1583, Naepoli; BN: $3 / 37633$.

7. Confessio fidei exhibita invictiss. imperator Carolo V. caesari aug. in comiciis avgvstae anno MDXXX, 1559, Wittebergae; BN: 2/67816.

8. De Concordiae quem vocant, a quibusdam Theologis, nomine quorumdam ordinam Augustanae Confessionis, edito, admonitio christiana, 1598, Hanoviae; BN: 3/40631

9. Defendis constitutis Karolus 3 Imperatori, 1599; no encontrado en BN.

10. Dictionarium medicum, vel, expositiones vocum medicinalium... cum latina interpretatione. Lexica duo in Hippocratem huic dictionario praefixa sunt, unum erotiani... alterum Galeni, 1564, Genevae; BN: R/24323.

11. Harmonia Confesionum fidei etc, 1581; no encontrado en BN.

12. Historia Belgica viri potissimum temporis, 1598; no encontrado en $\mathrm{BN}$.

13. Lugis Ecclesiae Catholicae sacrificii, eorumque omnium, quae in eo peraguntur solida iustaque defensio \& assertio... contra calumnias \& cavillationes lacobi Andreae Smidelin, 1570, Coloniae; BN: 3/69833.

14. Le vite de'Santi Padri, insieme col Prato Spiritvale..., 1580, Venetia; BN: 3/20192; 3/18266; BN: R/20429.

15. Lexicon Graecolatinvm. Ex R. Constantini aliorumque scriptis qui in hoc commentandi genere excelluerunt vtili compendio collectum: ac eorum omnium quae Operi maximè necessaria sunt accessione auctum atque illustratum, 1566, Lugduni; BN: 2/46477.

16. Lycophronis Chalcidensis Alexandra, sive Cassandra eruditissimis Isacii Tzetzis... commentariis (quae... nunc primum in lucem eduntur) illustratum... Adiectvs qvoqve est loannis Tzetzae variarum historiarvm liber, versibvs politicis ab eodem Graece..., 1546, Basileae; BN: 3/18357.

17. Meditationes Ethicae, sive Aristotelis Ethicorum Nikomaxeiwn... cum moribus sacris, id est, in sacra pagina descriptis, collata explicatio, per

66 En el Indice aparece la fecha de edición 1569. 
Petrum Martyrum Vermilium... et $D$. Andream Hyperium... cum notis \& lemmatibus logicis Rodolphi Goclenii, 1598, Lichae ad Veterim; BN: 2/67736.

18. Methodvs confessionis hoc est, ars, siue ratio et breuis quaedam uia confitendi: in qua peccata et eorum remedia plenissime continentur, 1546, Lugduni; BN: 2/67333.

19. Nonvs tomvs opervm divi Avrelii Avgvstini Hipponensis Episcopi, continens illius tractatus: hoc est, expositiones ad populum factas in nouum testamentum, cum aliis uarii generis opusculis, quorum indicem habet alterum huius paginae latus, 1550, Venetia; BN: 6-i/6338.

20. Novum Testamentum havd poenitendis sacrorum doctorum scoliis loan Benedicto... Huic tertiae... editione adiunctus est praeterea, 1563, Parisiis; BN: $3 / 40659$.

21. Postille maiores totius anni, cum glossis, quaestionibus \& figuris, expositiones Evangeliorum, ac Epistolarum totius anni continentes, 1555, Lugduni; BN: R/21184.

22. Pour traiclure of his sacred Magestie in his solitudes, 1549; no encontrado en $\mathrm{BN}$.

23. Rationes textus hab. et editionis. Vulgatae. Differentiarum fere sexmillium verborum in Psalmis omnibus aristantium, 1572, Venetia; BN: $2 / 4851$.

24. Sacrae Litaniae variae cum breui piaque quotidiana exercitatione, in gratiam catholicorum, 1596, Antuerpiae; BN: 3/60972.

25. Secreti diversi \& miracolosi, racolti dal Falopia \& approbati da altri medici di gran Fama, 1578, Venetia, BN: 3/42200.

26. Acidalius, Valentus: Valentis Acidalii in Q. Cvrtium animadversiones..., 1594, Francofurti ad Moenvm; BN: 3/37772.

27. Agathius: Agathius de bello gotthorum et aliis peregrinis historicis temporum suorum, 1518, Augustae Vindelicorum; BN: R/2611(1).

28. Alfraganus, Mohamed: Mvhamedis Alfragani Chronologica et astronomica elementa, e palatinae bibliotheca eteribus libris versa, expleta et scholiis expolita..., 1590, Francofurti; BN: R/18749.

29. Anriquez, Henricus Georgius: De regimine cibi atque potus et de caeterarum rerum non naturalium usu nova enarratio, 1594, Salamanticae; BN: R/20532.

30. Aretius, Benedictus: Commentarii in epistoiam ad Hebraeos, 1583, s.l.; BN: 5/4977/6. 
31. Aretius, Benedictus: Commentarii in epistolam D. Pauli ad Galatas, 1595, s.l.; BN: 5/4977/5.

32. Aretius, Benedictus: Commentarii in Evangelium d. nostri lesv Christi secundum Marcum, facile et perspicua methodo conscripti, 1579, Lausanae; BN: 5/4977.

33. Aretius, Benedictus: Commentarii in Evangelium loannis, 1595, s.I.; BN: 5/4977/3.

34. Aretius, Benedictus: Commentarii in Evangelivm Matthaei, 1595, s.I.; BN: 5/4977/1.

35. Aretius, Benedictus: Theologiae problemata, sev loci commvnes, et miscellaneae questiones, 1592, Genevae; BN: 3/36683-4.

36. Aretius, Benedictus: Commentarii in Epistolam D. Pauli ad Romanos, 1594, s.l.; BN: 5/4977/2.

37. Arias Montano, Benitus: Commentaria in duodecim prophetas, 1583, Antuerpiae; BN: 2/37123.

38. Aristoteles, Simplicius: La Phisica di Aristotile, tradotta di greco in volgare italiano, per Antonio Bruccioli, 1551, Venetia; BN: 3/33557.

40. Avila, lohannes de: Tratatus de sacro altaris misterio concitus á damino Inocentio Papa 3. ${ }^{\circ}, 1583$; no encontrado en BN.

41. Balbi, Girolamus: Ad Carolum V Imper de Coronatione, 1530, Lugduni; BN: R/21734-2.

42. Beroaldus: Heptalogos etc, 1534; no encontrado en BN.

43. Beust, loachimus von: Tractatus de ivre connvbiorvm: in tres partes divisvs.../antea editus per loachimum Beust... nunc postremo ab ipso authore recognitus \&... auctus; et commentarius in Tit. Instit. de Nuptiis, a Conrado Mausero... in Academia Witebergensi... traditus..., 1597, Lipsiae; BN: 3/27894.

44. Beze, Theodorus de: Ad repetitionem primam F. Claudii de Sainote, de rebus Eucharistiae controversis, Theodoris Bezue responsio, 1577, Genevae, BN: 3/56288.

45. Bocaccio, Giovanni: / Decamerone.../di nuovo riformato da Luigi Groto Cieco d'Andria... et con le dichiarationi \& auuertimenti di Girolamo Ruscelli, 1590, Venetia; BN: R/21486.

46. Bodinus Gio: De magorvm daemonomania, sev detestando lamiarum ac magorum cum Satana commercio, libri IV, 1590, Francofurti; BN: $3 / 21581$. 
47. Bodinus, Gio: Demonomania de gli stregoni, cioè fvrori, et malie de demoni..., $1592{ }^{67}$, Venetia; BN: 2/15264.

48. Bonfinus, Antonius: Symposion trimeron: sive, Antonii Bonfinii de pudicitia coniugali \& virginitate dialogi III/ Nunc primum ex bibliotheca loan. Sambuci V.C. in lucem prolati, 1572, Basileae; BN: 3/34953.

49. Bonifacius, loannius: De sapiente fructvoso epistolares libri quinque. Auctore loanne Bonifacio Societatis lesv, 1589, Burgis; BN: R/27943.

50. Borbonius, Nicolaus: Nicolai Borbonii Vandoperani Lingonensis, Nugarum libri octo/ $A b$ autore recens avcti et recogniti, 1540, Basileae; BN: $2 / 3231$.

51. Borcholtenus, lohannis: De gradibvs tratatvs in quo simul ad ostendendam uberiorem graduum utilitatem, de matrimonio et svccessionibvs ab intestato agitur, 1598, Helmstadii; BN: 2/55475.

52. Borrhaus, Martinus ${ }^{68}$ : In Aristotelis Politicorvm, sive de Repvblica libros octo, Martini Borrhai annotationes cumprimis eruditae, nuncque primum in lucem editae, 1545, Basileae; BN: 2/46601.

53. Boxhornius, Henricus: Anticvyckivs et commentariorvm de evcharistica harmonia, libri tres, adversvs Henrici Cuyckii... orationem paraeneticam, transsubstantiationem pontificiam, missae idolomaniam \& manducationem carnis lesu Christi corporalem/ Accessit iustitia reformationis..., 1598, Lugduni; BN: 2/55276.

54. Bredenbachius, Matthia: De dissidiis ecclesiae componendis, Matthias Bredenbachii sententia, 1558, Antuerpiae; BN: R/21224.

55. Brissoni, J.C.: De riptu nutiarum. Libri singularis, 1564, Parisiis; $\mathrm{BN}: 2 / 11664$.

56. Bucerus, Martinus: Libellus vere aureus $D$. Martini Buceri de vi et sacri ministerii, cum in genere, tum de singulis partibus eius..., 1562, Basileae; BN: R/2569.

57. Bucerus, Martinus: $M$. Bvceri de vera et falsa Caennae Dominicae administratione libri ll... Altera adversus B. Latomum responsio, 1546, Neuburgi; BN: 3/71973.

58. Bullingerus, Henricus: De scriptvrae sanctae avthoritate, certitudine, firmitate \& absoluta perfectione, deque Episcoporum... institutione

67 En el Índice aparece la fecha de edición 1542.

68 En el catálogo manual de la BN. el autor aparece como Cellarius, Martinus. 
\& functione, contra superstitionis tyrannidisque Romanae antistites, 1544, Tiguri; BN: 3/24885.

59. Bullingerus, Henricus: Tractatio verborvm Domini, in domo Patris mei mansiones multae sunt \&C. ex XIIII. cap. Euang. secundum loann..., 1561, Tiguri; BN: 2/55436.

60. Camerarius, loachimus Pabergensis: lachimi Camerarii Bapenbergensis Epistolarvm familiarivm libri VI. Nunc primum post ipsius obitum sigulari studio a filiis editi..., 1583, Francofurti; BN: U/1940.

61. Camillus, D'Ausilius Carmelitanus: Summario dell aulichissima origine della religione carmelitana, 1595; no encontrado en BN.

62. Camillus, Giulius: Tvtte l'opere di M. Givlio Camillo Delminio. II Catalogo delle quali s ha nella seguente facciata; nvovamente ristampate con la tauola delle cose notabili et con le postille in margine, 1581, Venetia; BN: $3 / 3723$.

63. Cardanus, Hieronymus ${ }^{69}$ : Hieronymi Cardani... in $\mathrm{Cl}$. Ptolemaei... IIII. de astrorum iudiciis... libros commentaria.../ Praeterea, eiusdem ... Geniturarum XIII... exempla, 1550, Lugduni; BN: R/17761.

64. Carioni, Iohanne: Chronicon Carionis expositum et auctum... usque ad Carolum quintum imperatorem, a Philippo Melanchthone \& Casparo Peucero, 1592, Genevae; BN: $3 / 35134^{70}$.

65. Casus, lohanne: Sphaera civitatis hoc est, res publicae recte ac pie secundum leges administrandae ratio..., 1593, Francofurti ad Moenum; BN: 2/66271.

66. Castiglione, Baldassare: / Libro del Cortegiano... Nuovamente... revisto per $M$. Lodovico Dolce..., 1556, Venetia; BN: R/8234.

67. Castro, Alphonsus de: F. Alfonsi A. Castro zamorensis... De iusta haereticorum punitione libri tres, nunc recens accurate recogniti, 1549, Venetia; BN: R/26318.

68. Cavallini, Casparus ${ }^{71}$ : Tractatvs de eo qvod interest... Accessit... discussio de inofficiosis testamentis, donationibus \& dotibus... Discutitur etiam quaestio una... de donatione in contractu matrimonii celebrata. Omnia a Gaspare Caballino.. in unum congesta, 1574, Venetia; BN: 2/6498.

\footnotetext{
69 En el catálogo manual de la BN, el autor aparece como Müller, Johann.

70 En el catálogo manual de la BN aparece esta signatura, pero no coincide con el título del ejemplar consultado

71 El compilador es G. Cavallini, pero el autor es Carolus Molineus.
} 
69. Cavallini, Casparus ${ }^{72}$ : Tractatvs diuidui \& indiuidui $c v m$ nova et analytica tam in theoria, quam in praxi declaratione legum omnium eius materiae/ compilatore Gaspare Caballino, 1576, Venetia; BN: 2/13607.

70. Cavallini, Casparus ${ }^{73}$ : Tractatus dividui \& individui cum nova et analytica tam in theoria, quam in praxi declaratione legum omnium eius materiae/ compilatore Gaspare Caballino, 1576, Venetia; BN: 2/12782.

71. Celso, Aulus Cornelius: De re medica. Libri VIII item Q. Sereni liber de Medicina, 1563, Patavii; BN: R/18524.

72. Sadecle, Antonius ${ }^{74}$ : Locvs De verbo Dei scripto ad versvs hvmanas traditiones, theologice et Scholastice tractatus. vbi agitur de vera methodo Theologice simul et scholastice disputandi, 1582, Morgiis; BN: 3/38390.

73. Sadecle, Antonius ${ }^{75}$ : Locvs de vnico Christi sacerdotio et sacrificio, aduersus commentitium missae sacrificium, theologice et Scholastice tractatus, 1581, Genovae; BN: 3/58435.

74. Cheffontaines, Christophorus de: Fidei maiorvm nostrorvm defensio qua haereticorvm saecvli nostri astus ac stratagemata deteguntur... Frate Christophoro a Capite Fontivm... auctore, 1575, Antuerpiae; BN: 2/10755.

75. Chemnitius, Martinus: De dvabvs natvris in Christo. De hypostatica earvm vnione. De commvnicatione idiomatvm, et de aliis quaestionibvs independentibvs. Libellus ex scripturae sententiis... denuo recognitus et retextus, 1580, Lipsiae; BN: 3/24382.

76. Chrisostomus, loannis: Diui loannis Chrysostomi episcopi Constantinopolitani in sanctum lesu Christi Evangelium secundum Mathaeum commentarii luculentissimi omnibus verbi diuidi studiosis necessarii opvs perfectvm, 1545, Parisiis, BN: 3/42159.

77. Chytraeus, Davidis ${ }^{76}$ : De tribus nostrae aetatis Caesaribus Augustis, Carolo V. Ferdinando I, Maximiliano II, orationes, a Davide Chytraeo datae adolescentibus in schola recitandae, 1583, Wittebergae; BN: 2/4065.

78. Chytraeus, Davidis ${ }^{77}$ : Chronicon saxoniae \& vicini orbis arctoi, 1592, Lipsiae; BN: 3/64441-4.

72 El compilador es G. Cavallini, pero el autor es Carolus Molineus.

73 El compilador es G. Cavallini, pero e! autor es Carolus Molineus.

${ }^{74}$ En el catálogo manual de la BN, el autor aparece como Chandieu, Antoine, La Roche de.

75 En el catálogo manual de la BN, el autor aparece como Chandieu, Antoine, La Roche de.

36 En el catálogo manual de la BN el autor aparece como Kochhaff, David.

77 En el catálogo manual de la BN el autor aparece como Kochhaff, David. 
79. Chytraeus, Davidis ${ }^{78}$ : Chronicon saxoniae \& viciniarum aliquot Gentium: ab anno 1500 vsque ad 1593, 1593, Lipsiae; BN: 3/59635.

80. Ciconia, Vincentius: Enarrationes in Psalmos Davidis, 1568, s.I; BN: $3 / 62168$.

81. Cochlaeus, lohann: Historia loannis Cochlaei de actis et scriptis Martinis Lutheri Saxonis chronographicè ex ordine ab anno... MDXVII usque ad annum MDXLVI inclusiue, fideliter descripta et ad posteros denarrata, 1568, Coloniae; BN: 3/76746.

82. Cochlaeus, lohann: Historia loannis Cochlaei de actis et scriptis Martinis Lutheri Saxonis, chronographicè ex ordine ab anno... MDXVII usque ad annum MDXLVI inclusiuè, fideliter descripta et ad posteros derrata, 1568, Coloniae; BN: $3 / 25520$.

84. Cochlaeus, lohann: Historia loannis Cochlaei de actis et scriptis Martinis Lutheri...; chronographicè ex ordine ab anno... MDXVII usque ad annum MDXLVI inclusiu, fideliter descripta et ad posteros derrata, 1568, Coloniae; BN: $3 / 66287$.

85. Cochlaeus, lohannes: Historia loannis Cochlaei de actis et scriptis Martini Lvtheri Saxonis, chronographice, ex ordine ab anno Domini MDXVII vsque ad annum MDXLVI inclusiue fideliter conscripta \& ad posteros denarrata, $1565^{79}$, Parisiis; BN: 3/65150.

86. Corasius, lohannis: Tractatvs de ivris arte dvorvm clarissimorvm ivrisconsvltorvm, loannis Corasii, et loachimi Hopperi Phrisii, 1582, Coloniae Agrippinae; BN: 2/3795.

87. Corderius, Maturinus: Admonitiones de svis colloquiis, versibus scriptae. Quomodo legenda sint a pueris haec colloquia, 1564, s.I.; BN: $2 / 56166^{80}$

88. Corderius, Maturinus: Matvrini Corderii De corrupti sermonis emendatione \& Latine loquendi ratione liber unus. Index Gallicarum dictionum Latine in hoc libello redditarum, 1539, Lugduni; BN: 3/38959.

89. Corsettus, Antonius: Repertorium Antonii Corserti... ad Nicolai Abbatis Panormitani Commentaria super Decretalium \& Clementinarum libros; item ad consilia et quaestiones... aliorum in eadem materia..., 1588 , Venetia; BN: 3/27091.

78 En el catálogo manual de la BN el autor aparece como Kochhaff, David.

$7^{\circ}$ En el Índice de la BN aparece la fecha de edición, 1568.

80 En la ficha del catálogo manual consta el año de edición erróneo: 1585. 
90. Da Milano, Giulius ${ }^{81}$ : Homiliae clarissimi viri, Celeberrimique, in orbe concionatoris, fratis Hieronymi Sauonarolae Ferrariensis ordinis praedicatorum in totum libellum Ruth, ac in totum Michaeam \& in tria alia scripturae loca, opus nunc primum ex Hetrusca lingua..., 1556, Salamanticae; BN: R/29659.

91. Damhouderius, lodocus: Practica rervm criminalivm...,1558, Lugduni; BN: 2/69003.

92. Daneaus, Lambertus: Ad Roberti Bellarmini Dispvtationes Theologicas/ De rebus in religione controuersis Lamberti Danaei responsio..., 1596, Genevae; BN: 2/69713.

93. Daneaus, Lambertus: Christianae isagoges ad christianorum theologorum locos communes, libri II,1588, Genevae; BN: 3/17056.

94. Daneaus, Lambertus: Isagoges christianae pars quarta: quae est de salvtaribus Dei donis erga ecclesiam. In qua \& de Bonis eclesiasticis \& de electione Dei, sacramentis \& vita etterna agitur, reliquisque capitibus, quae sequens Index continer..., 1591, Genevae; BN: $5 / 7800$.

95. Daneaus, Lambertus: Tractatuvs de Antichristo, in qvo antichristiani regni logvs, tempvs, forma, ministri, fulcimenta, progressio \& tandem exitium \& interitus ex Dei verbo demonstratur, bi etiam aliquot difficiles antea \& obscuri tum Danielis..., 1582, Genevae; BN: 3/21067.

96. Daneaus, Lambertus: Vetvtissimarvm primi mvndi antiqvitatvm sectiones, seu libri IIII, tvm ex sacris, tvm aliis autoribus, 1596, Genevae; BN: $3 / 2832$.

97. Daneaus, Lambertus: Ad Nicolai Selnecceri librvm, qvi inscribitvr necessaria et brevis repetitio etc, in qvo exegesis Saxonica oppugnatur, 1579, Genevae; BN: 3/28436.

98. Dasypodius, Conradus: Cvnradi Dasypodii institvtionvm mathematicarvm volvminis primi erotemata Logisticae, Geometriae, Sphaerae, Geographiae, 1593, Argentorati; BN: 2/66629.

99. Desiderius, Guidone: Epitome operis perqvam vtilis morbis curandis Valesci de Taranta in septern congesta libros. Autore Guidone Desiderio Delphinate medico inclyti monasterii diui Antonii Viennensis dioecesis, 1560, Lugduni; BN: 2/19335.

81 También Savonarola, Geronimo. 
100. Dionigi da Fano, Bartholome: Compendio historico del Vecchio e del Nuouo Testamento: cavato dalla Sacra Bibblia..., $1586^{82}$, Venetia; BN: 3/41395.

101. Dionigi da Fano, Bartholome: Compendio historico del Vecchio e del Nuouo Testamento: cavato della Sacra Bibblia..., 1590, Venetia; BN: 2/25595.

102. Dousa, lohan van der: lani Dovsae nordovicis Annales, rervm a priscis Hollandiae Comitibvs per CCC.XLVI. annos gestarum continuata serie memoriam complectentes. Nunc primitvs in vnvm metricae historiae corpus redacti, atque in $X$. libros tributi ac dispartiti..., 1599, Hagae-Comitis; BN: 2/21683.

103. Donatus, Ciovanni Paolus: Brevis tractatvs de casibvs Sedi Apostolicae reseruatis. in qvo qvicqvid hactenus cum á sanctis Patribus tum etiam à scholasticis Theologis dictum est disputatur, 1581, Augustae Taurinorum; BN: 3/20545.

104. Dorneus, Gerardus: Fascicvlvs paracelsicae medicinae veteris et non novae, per floscvlos chimicos et medicos tamquam in compendiosum promptuarium collectus... Cum elvcidationibvs hvivs..., 1581, Francoforti ad Moenum; BN: 2/1657.

105. Erasmus Rotterodami, Desiderius: D. Erasmi Roterodami De dvplici copia, verborvm ac rervm commentarii dvo: multa accessione, nouisque formulis locupletati/ Addita sunt doctiss. commentaria M. Veltkirchii oratoriae professoris in schola Vuitterbergensi, 1566, Coloniae Agrippinae; BN: 2/4585.

106. Erasmus Rotterodami, Desiderius: D. Erasmi Roterodami Opvs de conscribendis epistolis ex postrema authoris recognitione emendatius editum/ Item loannis Lodovici Vivis... libellus vere aureus. Conradi Celtis methodus Christophori Hegendorphini epitome. Una cum indice..., 1569, Coloniae; BN: 3/71257.

107. Erasmus Rotterodami, Desiderius: Epistola nuncvpatoria ad Carolvm Caesare. Exhortatio ad studium Euangelicae lectionis paraphrasis in Euangelium Matthaei... ${ }^{83}$, 1525; no encontrado en BN.

108. Estrada: Materia de hereci, atque infidelitate theologica xa methodus suaristicae scholae a Pe. Nicolao Scholaetici moderatore et cui

82 En el Índice de la BN aparece la fecha de edición, 1584

83 Con este título sólo existen dos ejemplares en España, en Burgos y Salamanca. 
diente Bre. Dno. Antonio Josef de Amerqta in collegio Dr. Hermeneg. Loci societatis Jesu civitatis Hispalensis, 1521, s.l.; BN: Mss/8057.

109. Everardus, Nicolaus: Loci argvmentorvm legales, $1568^{84}$, Lugduni; BN: 2/55441; 3/27482.

110. Ferus, lohannes: Epitome sermonvm... D. loan, Feri dominicalivm vtrivsque cvm hiemalis tum aestivalis partis conscripta et diversis temporibvs ... per loannem a Via... nunc primum in lucem aedita. Huic adiectae sunt..., 1562, Lugduni; BN: 3/41241; 8/17514.

111. Ferus, lohannes: Postillae sive conciones F. loan. Feri... in Epistolas \& Evangelia, quae ad Adventu ad Pascha vsque in Ecclesia Christi legi consueverunt, 1558, Lugduni; BN: 3/31029.

112. Ferus, lohannes: Sermones qvadragesimales in tria posteriora capita Lib. I. Esdrae \& Historiam Evangelicam de muliere peccatrice: Moguntiae pro concione habiti, per fratem loannem Ferum... Opera lonnis Latomi..., 1554, Lugduni; BN: 3/57726.

114. Ferus, lohannes: R.D. loan. Feri, Mogvntinae ecclesiae concionatoris, in sanctorum festa quae per totum annum in catholica celebrantur ecclesia postillae/ nunc demum per R.D. loannem à Via... latinitate donatae,1562, Lugduni; BN: 3/26742.

115. Fiamma, Gabriel: De discorsi del R.D. Gabriel Fiamma, Canonico regolare lateranense, sopra L'Epistole, Evangeli di tutto l'anno. Parte prima, 1574 , Venetia; BN: 5/7634.

116. Fortius Ringelberius, loachinus: Opera, quae proxima pagina enumerantur, 1531, Lugduni; BN: 3/65896.

117. Fuchsius, Leonhardus: De historia stirpivm commentarii insignes... Scholiis in singula prope capita... adiectis \& plantarum voces Gallicas passim exprimentibus. Accessit is ... vocum difficilium \& obscurarum... explicatio. Vna cum triplici indice..., i546, Parisiis; BN: 2/64227.

118. Fuchsius, Leonhardus: De sanandus totivs hvmani corporis, eiusdemque partium tam internis quam externis malis libri $\mathrm{V}$. accurata diligentia conscripti, Leonharto Fuchsio medico autore..., 1546, Lugduni; BN: $2 / 54765$.

119. Fuchsius, Leonhardus: Hippocratis sexti epidemion libri particvla prima, Leonardo Fvchsio interprete, 1537, Haguenau; BN: R/21400.

84 En el Índice aparece la techa de edición 1558. 
119. Fuchsius, Leonhardus: Methodvs sev ratio compendiaria perueniendi ad veram solidamque medicinam, 1548, Lugduni; BN: 3/6765.

120. Garcaey, lohannes ${ }^{85}$ : Astrologiae Methodus, 1576, Basileae; BN: 3/16293.

121. Gauricus, Luca: Calendarivm ecclesiasticvm novvm, ex sacris literis, probatisque sanctorum Patrum synodis excerptum, iuxta omnipotentis dei mandata in Veteri Testamento mosi data..., 1552, Venetia; BN: $3 / 63423$.

122. Gauricus, Luca: Lvcae Gavrici Episcopi Ciuitatensis Tractatvs ivdicandi conversiones sive revolvtiones natiuitatum, 1560, Romae; BN: 2/69118.

123. Geber ${ }^{86}$ : Gebri Arabis philosophi ac alchinistae acvtissimi, De Alchemia Traditio summae perfectionis in duos libros divisa. Item: Liber investigationis magisterii eiusdem, 1598, s.I.; BN: 3/14293.

124. Gelli, Gio Baptista: Le circe di Gio Battista Gelli, academico fiorentino..., 1595, Venetia; BN: R/23669.

125. Gesualdo, M. Gio Andrea: // Petrarcha con l'espontione di $M$. Gio. Andrea Gesvaldo. Nvovamente ristampato, e con somma diligenza corretto et ornato di figvre, 1581, Venetia; BN: R/11380.

126. Granada, Ludovicus: Conciones de praecipvis santorvm festis, a festo beatissimae Miariae Magdalenae vsque ad finem anni, 1598, Lugduni; BN: R/28125.

127. Granada, Ludovicus: Concionum de tempore quea post fectum etc, 1582, Salamanticae; BN: R/31981.

128. Granada, Ludovicus: Concionvm de tempore, 1575-76, Olysipone; BN: R/31976; R/31974-5.

129. Gruterus, lanus: lani Grvteri animadversiones in L. Annaei Senecae opera... / His additae Nicolai Fabri annotationes ad Senecae patris controuersias \& filii Apocolocynthosin, 1594-95, Genevae; BN: 2/68766.

130. Grynaeus, lohann lakobus: Enarratio brevis psalmi CXXXIII. De concordia Fidelium; CX. De lesu Christo Immanuele; XIX. De Studio Theologico, Tradita in Academia Basiliensi..., 1579, Genevae; BN: $3 / 21060$.

85 En el catálogo manual de la BN, el autor aparece como Gartze, lohann.

86 En el catálogo manual de la BN, el nombre de este autor aparece como Cremona, Gerardo. 
131. Guicciardini, Francesco: / qvattro vitimi libri dell' Historie d'Italia de M. Francesco Gvicciardini gentil'hvomo fiorentino. Nvovamente con somma diligenza restampati, \& ricorretti; con lággiunta de'Sommarii a ciascadun libro..., 1564, Parma; BN: 5/7642.

132. Guinterius, lohannes ${ }^{87}$ : Postillae sive conciones, 1558, Lugduni; BN: $3 / 31029$.

133. Harpprechtus, lohannes: Commentaria in celebrem titulum institutionum juris imp. Justiniani, de publicis judiciis: quibus insigniores quaestiones criminales sedulo \& accurate discutiuntur, atque explanantur..., 1599, Francofurti; BN: 2/6495.

134. Hellopaeus Zikzai, Valentinus: De Sacramentis in genere, sive, de tota re sacramentaria, Tractatio, permoderstè simul \& eruditè scripta..., 1585, Sumptibus; BN: 3/39413.

135. Hemichius, Georgius: Heriodus graeco latinus cimischematisimis artificium etc, 1580; no encontrado en BN.

136. Hemingius, Nicolaus: Enarratio viginti et vnivs psalmorvm Davidis (qvi sunt ordine primi) in qua multae doctrinae explicantur..., 1592, Apud Petrum Santandreanum; BN: 3/32082.

137. Herdesianus, Christophus: Refvtatio dogmatis de fictitia carnis Christi omnipraesentia, et reali idiomatum in ipsis naturis communicatione, ex verbo Dei, et perpetuo ecclesiae eduersus nestorium et eutychetem consensu. Auctore Christiano Hessiandro cvm Theodori Bezae Vezelii..., 1571. Apud loannem Crispinum; BN: 3/24347.

138. Hippocrates: Hippocratis aphorismi digesti in ordinem secundum locos congruentium secum materiarum: cum breui \& dilucida expositione singulis aphorismis ex Galeno supposita, quae integrorum vice commentariorum esse possit...,1555, Lugduni; BN: 3/31379.

139. Hippocrates: Hippocratis aphorismi, id esi, selectae maximeque ratae sententiae, interprete Guglielmo Plantio Cenomano. Galeni in eosdem commentarii septem, ab eodem Plantio latine redditi et annotationibus illustrati..., 1561, Lugduni; BN: 7/12435.

140. Hippocrates: Libri epidemiorvm Hippocratis primvs, tertivs, et sexivs/ cum Galeni in sos commentariis, 10. Vassaeo meldensi interprete..., 1550, Lugduni: BN: $3 / 31382$.

87 También Wild, lohann. 
141. Hotomanus, Francescus: Franc. Hotomani... variarum disputationum volumen primum..., 1569, Lugduni; BN: 5/6945.

142. Innocentius III, Papa: Summi Pontificis Innocentii Tertii de sacro altaris mysterio libri sex..., 1570, Salamanticae; BN: R/28359.

143. Iunctinus, Franciscus: Speculum Astrologiae: quod attinet ad iudiciariam rationem natiuitatum atque annuarum revolutionum, cum nonnullis approbatis astrologorum sententiis, 1573, Lugduni; BN: GM 70m.

144. Iansenius, Cornelius: Cornelii Iansenii episcopi gandavensis Homiliae in Evangelia avae dominicis diebus in ecclesia populo proponi solent, ex quatuor commentariorum in concordiam Euangelicam libris..., 1578, Lugduni; BN: 2/39869.

145. Iansenius, Cornelius: Cornelii lansenii... commentariorum in suam concordiam, ac totam Historiam Euangelicam artes qvatvor..., 1587, Venetia; BN: $3 / 8979$.

146. Kling, Melchior: Dn. Melchioris Kling, ivreconsvlti clarissimi, in quatuor institutionum iuris principis lustiniani libros, enarrationes, de integro in gratiam studiosorum \& praxim forensem senctentium..., 1550, Lugduni; BN: $3 / 27994$.

147. Lagus, Conradus: Methodica ivris vtrivsque traditio omnem omnium titulorum, tam Pontificii, quam Caesarei iuris materiam \& genus, glossarum intem \& interpreum abstrusiora vocabula scienter \& summatim explicata..., 1545, Parisiis; BN: 2/3788.

148. Lascovius, Petrus: Theorematvm de pvro et expresso Dei verbo, tam scriptis quam viua voce tradito \& pari vtriusque authoritate nuper in gymnasio Claudioiesuipolitano in Transylvania a nouis societatis ludae Monac his propositorum, examen \& refutatio..., 1584, Genevae; BN: 3/56753.

149. Lavaterus, Ludovicus: Historia de origine et progressv controuersiae sacramentariae de Coena Domini, ab anno... MDXXIIII, usque ad annum MDLXIII, deducta, 1563, Tiguri; BN: 3/39586.

150. Lenzi, Marianus: Philone et Sophia D'amore et desiderio dialogo primo, 1549, Venetia; BN: 2/70541.

151. Leonis Africani, loannis: De L'Afriqve, contenant les nauigations des capitaines portugalois \& autres, faites audit pais, iusques aux indes, tant orientales, que occidentales, parties de Perse, Arabie Heureuse, Pierreuse \& Deserte, 1556, Lyon; BN: Afr. 1552.

152. Leonis Africani, loannis: loannis Leonis Africani, De totivs Africae descriptione libri IX. Quibus non solum Africae regionum, insularum \& 
oppidorum situs, locorumque interualla accurate complexus est, sed Regum familias, bellorum causas \& euentus..., 1556, Antuerpiae; BN: $\mathrm{R} / 25410$.

153. Livius, Titus: T. Livii Patavini historiarvm ab vrbe condita, decas quarta, 1554, Basileae; BN: R/i-302.

154. Lonicerus, Philippus ${ }^{88}$ : Theatrum historicum siue promtvarivm illvstrivm exemplorvm, ad honeste, pie, beateqve vivendvm cvivsvis generis, \& conditionis homines informatium, ex antiquis simul acrecentioribus sacrarum..., 1590, Francofurti; BN: 3/21000.

155. Lusitanius, Amatus ${ }^{89}$ : Amati Lvsitanii, medici physici praestantissimi Curationum medicinalium Centvriae dvae, tertia et quarta, cum indice omnium curationum \& rerum memorabilium quae ipsis centuriis continentur, 1565, Lugduni; BN: R/29260.

156. Martius Narniensis, Galeottus: Galeottvs Martivs Narniensis, de doctrina promiscva, 1552, Lugduni; BN: 3/61714.

157. Melanchthonis, Filippus: Argvmentorvm theologicorvm pars sexta (-octava) contexta ex scriptis... Philippi Melanchthonis/ opera \& studio Christophori Peselii sacrae theologiae doctoris, 1584-1589, Neapoli Palatinorum; BN: 5/7662.

158. Melanchthonis, Filippus: Argvmentorvm theologicorvm pars sexta (-octava) contexta ex scriptis... Philippi Melanchthonis/ opera \& studio Christophori Peselii sacrae theologiae doctoris, 1584-1589, Neapoli Palatinorum; BN: 5/7662.

159. Melanchthonis, Filippus: Argvmentorvm theologicorvm pars sexta (-octava) contexta ex scriptis... Philippi Melanchthonis/ opera \& studio Christophori Peselii sacrae theologiae doctoris, 1584-1589, Neapoli Palatiriorum; BN: 5/7662.

160. Melanchthonis, Philippus: Loci commvnes theologici, summa cura ac diligentia postremùm recogniti, \& aucti, per Philippum Melanthonem. Cum tribus amplissimis indicibus..., 1562, Basileae; BN: 3/30765.

161. Mendoza, Alphonsus de: Fratris Alphonsi Mendozae, ex ordine eremitarvm $D$. Augustini... Quaestiones quod libeticae et relectio de Christi regno ac dominio...,1596, Salamanticae; BN: R/29161.

\footnotetext{
88 También Hondolffius, Andreas.

89 En el catálogo manual de la BN, el autor aparece como Rodríguez de Castello Branco, Joao.
} 
162. Molinaeus, Carolus: Commentarivs ad edictvm Henrici Secvndi contra paruas Datas \& abusus curiae Romanae, \& in antiqua edicta \& Senatusconsulta Franciae contra Annatarum \& id genus abusus..., 1552, Lugduni; BN: 3/24346.

163. Molinaeus, Carolus: De eo qvod interest, tractatvs D. Caroli Molinaei... Accessit brevis et analitica discussio, de inofficiosis testamentis, donationibus et dotibus, cum multorum iurium enucleatione. Discvititvr etiam quaestio vna ad materiam I. si vnquam. C. de reuoc. Donat,1598, Coloniae Agrippinae; BN: 2/3988.

164. Mornay, Philippus de: De la verite de la religion Chrestienne. Contre les Athées, Epicuriens, Paiens, luifs, Mahumedistes, et autres Infideles..., 1582, Parisiis; BN: 2/68542.

165. Musculus, Wolfgang: Loci commvnes Sacrae Theologiae iam recens recogniti \& emendati... Adiectus est etiam rerum et verborum memorabilium multo quam antea copiosior index, 1587, Basileae; BN: 2/55213.

166. Nabod, Valentius ${ }^{90}$ : Enarratio elementorvm astrologiae, in qva praeter alcabicii, qvi arabum doctrinam compendio prodidit, expositionem... A Valentino Nabod, amplissimi Senatus Coloniensis Mathematicarum ordinario, 1560 , Coloniae; $\mathrm{BN}: 3 / 13150$.

167. Omar, Tiberiades: Omar De natiuitatibus et interrogationibus/ nuper castigatus et in ordinem redactus per d. Lucam Gauricuz... artium doctorem egregium comitez palatinum atque prothonotarium apostolicuum cum multis additionibus, 1535, Venetia; BN: R/17898.

168. Oña, Petrus de: Svper octo libros Aristoteles De Physica abscvltatione commentaria: vna cvm qvaestionibus vigillantissimo pastore nostro $\mathrm{Ma}$ gistro Generali Frate Fsco Salazar. Authore P.F. Petro de Oña, burg. in Sacra Theologia doctore, prouinciae Castellae..., 1593, Compluti; BN: R/28443.

169. Orozco, Alphonsus de: Commentaria qvaedam in Cantica Canticorvm, nunc denuo ex doctorum dictis congesta, per Fratem Alphonsum ab Orozco Augustinianum. Accessere quadraginta quatuor annotationes in eadem Cantica, Deiparae Mariae Virginis festiuitatibus accommodatae, 1581, Burgis; BN: R/28276.

170. Orozco, Alphonsus B.: Declamationes decem et septem, pro aduentu Domini nostri lesu Christi et vsque ad Septuagesimam..., 1569, Mantuae; BN: R/25417.

90 En el İndice en el lugar del autor aparece el nombre del editor, Birckman. 
171. Osorio, Hieronymus: $D$. Hieronymi Osorii Lvsitani, episcopi Sylvensis. De regis institvtione et disciplina, lib. VIII, ad serenissimvm et invictissimvm Portvgaliae regem, Sebastianvm..., 1571, Olysipone; BN: R/28727.

172. Ovidio Nason, Publio: Epistole d'Ovidio di Remigio Fiorentino divise in dve libri. Con le dichiaratione in margine delle Fauole, e dell'Historie et con la Tauola dell'Epistole..., 1586, Venetia; BN: 3/28251.

173. Palma, Petrus Victore Caietanus ${ }^{91}$ : Paradigmata de qvatvor lingvis orientalibvs praecipvis, Arabica, Armena, Syra, Aethiopica. Domino Illvstrissimo D. Amplissimo à Latere, sanctiss. in Christo Domino Patris ac Domini Apostolici, Clementis VIII, 1596, Parisiis, BN: R/18029.

174. Panigarola, Francesco: Dichiaratione de i Salmi di David fatta dal R.P.F. Francesco Pangarola, minore osseruante, 1588, Bergamo; BN: $3 / 41053$.

175. Panigarola, Francesco: Dichiaratione de i Salmi di David, fatta dal R.P.F. Francesco Panigarola, minore osseruante..., 1586, Turino; BN: 3/35402.

176. Parpera, Giacintus: Vita mirabile et dottrina santa della Beata Caterina da Genova nella quale si contiene vna vtile e catholica dimostratione \& dichiaratione del Purgatorio, 1568, Fiorenza; BN: R/19530.

177. Peucerus Budissini, Casparus: Commentarivs, de praecipvis divinationvm generibvs in qvo a prophetiis.../ recognitus ultimo et auctus ab avthore ipso Casparo Peucero. Addita, singulis voculis et sententiis Graecis, sua interpretatione, $1593^{92}$, Francofurti; BN: 3/42469.

178. Pezellus, Christophorus: In primvm librvm Moisis, qui inscribitur Genesis Commentarivs Christophori Pezelli Theologiae doctoris \& professoris in ecclesia \& schola Bremensi. Propositvs in gymnasio scholae bremensis \& nunc primum in lucem editus à M. Avgvsto Sagittario Dresdensi..., 1599, Neostadii; BN: 3/18495.

179. Pezellus, Christophorus: Quinta pars obiectionvm et responsionvm theologicarm: Qua sunt collectae ex scriptis optime de ecclesia \& scholis meriti D. Philippi Melanchthonis, 1592, Neapoli; BN: 5/7310.

180. Pighius, Albertus ${ }^{93}$ : De libero hominis arbitrio \& divina gratia, libri decem nunc primum in lucem editi..., 1542, Coloniae; BN: 2/71167.

91 En el catálogo manual de la BN, el autor aparece como Cayet Palma, Pierre Victor.

92 En el ínuice aparece la fecha de edición 1543.

93 En el catálogo manuai de la BN, el autor aparece como Pigghe, Albert. 
181. Pisis, Rainerius de: Pantheologiae svmmam vniversae Theologicae veritatis, vna et plvrimarvm vtrisque testamenti avctoritatvm lucidam expositionem complectentis, 1580, Brixiae; BN: 6-i 6700.

182. Plautus, Titus M. Accius: $M$. Accivs Plavtvs ex fide, atqve avctoritate complvrium librorum manuscriptorum opera Dionys. Lambini Monstroliensis emendatus ab eodemque commentariis explicatus..., 1595, Genevae; BN: R/21350.

183. Plutarchus: Plvtarchi Chaeronensis, Svmmi et philosophi et historici parallela id est Vitae Illvstrivm virorvm graecorvm et romanorum, vtilissima historia expositae, atque inter se comparatae, 1580, Francoforti ad Moenum; BN: 2/55980.

184. Pontanus, Giovannus: De aspiratione libre duo Charon. Dialogus Antonius..., 1519, Venetia; BN: R/38663 .

185. Pontanus, Giovannus: Ioannis loviani Pontani Opera omnia solvta oratione composita, 1518, Venetia; BN: R/33891.

186. Porta Neapolitani, loannis Baptista: 1o. Baptistae Portae Neapolitani, Magiae natvralis libri viginti, in qvibvs scientiarum naturalium diuitiae \& deliciae demonstrantur..., 1597, Francofurti; BN: 3/3767.

187. Pulvaei, Adrianus: Adriani Pvlvaei LL. doctoris et in Suprema parisiorum Curia aduocati. De nuptiis sine parentum consensu non contrahendis, libri dvo in quibus edictum Henrici eius nominis II. Francorum Regis ad eam rem pertinens explicatur, 1579, Parisiis; BN: 2/6711.

188. Ramirez, lohannes: Expositio Bullae Alexandri Tertii, de confirmatione Ordinis Militiae S. lacobi/authore Doctore loanne Ramirez eiusdem ordinis professo, inquisitore Apostclico in Regno Nauarra, 1599 94, Burgis; BN: R/29847.

189. Rescio, Stanislaus: Spongia qva abstergvntvr convitia et maledicta eqvitis Poloni contra lesvitas, 1592, Cracovia; BN: U/5583.

190. Rossello, Thimoteus: Della svmma de secreti vniversali in ogni material Parte prima (-seconda) di Don Thimotheo Rossello, si per huomini \& donne, di alto ingegno, come ancora per Medici \& ogni sorte di artefici industriosi \& a ogni persona virtuosa accommodate, $1575{ }^{95}$, Venetia; BN: 7/15786.

94 En el índice aparece la fecha de edición 1549.

95 En el Índice aparece la fecha de edición 1588. 
191. Sabunde, Raymundus: Theologia naturalis sive Liber creaturar $u$ specialiter de homine \& de natura eius in quantum homo..., 1541, Lugduni; BN: R/21066.

192. Samarinus, Franciscus: Thesavrvs sacerdotalis iuxta consvetvdinem S. Romanae ecclesiae, sacrique concilii Tridentini fanctiones, qvibvsqve sacerdotibvs, episcopis, et praelatis, nencon cunctis Christi fidelibus pernecessarius, ex diversis voluminibus compendiose collectus..., 15(roto), Venetia; BN: 3/27615.

193. Sansovino, Francesco: Del secretario di M. Francesco Sansovino libri VII. Nel quale si mostra \& insegna il modo di scriver lettere acconciamente \& con arte, in qual si uoglia soggetto..., 1584, Venetia; BN: $\mathrm{R} / 27094$.

194. Sansovino, Francesco: Historia Vniversale dell'origine et imperio de'Turchi raccolta da F. Francesco Sansovino... Nella quale si contengono le leggi, gli ufficii \& i costumi di quella natione, cosi in tempo di pace, come di guerra..., 1573, Venetia; BN: 2/47905.

195. Santo Tomas: Cathena aurea Angelici doctoris diui Thomae Aquitanis sacrarum literarum peritissimi, Cathena aurea in Euangelium Luce et celeberrimus..., 1544, Lugduni; BN: 2/69695.

196. Scala, Paolus della: Pali Principis de la Scala et hvn, Marchionis Veronae \&c Domini Crevtzburgi prvssiae. Miscellaneorvm de rervm cavssis, et svccessibus \& de secretiore quadam methodo qua euersiones omnium regnorum vniuersi orbis \& futurorum series erui possint, libri septem, 1570, Coloniae Agrippinae; BN: 3/18071; R/180888(1).

197. Scaligerus, losephus: losephi Scaligeri, lul. Caes. F. epistola de vetvstate et splendore gentis Scaligerae, et lul. Caes. Scaligeri vita. Iul. Caes. Scaligeri Oratio in lucti filioli Avdecti, $1594{ }^{96}$, Lugduni; BN: R/35048.

198. Scaligerus, lulius Caesar: Ivlii Caesaris Scaligeri Exotericarvm exercitationum lib. XV de subtilitate ad Hieronymvm Cardanvm, 1576, Francofurti; BN: R/20648.

199. Scaligerus, lulius Caesar: Ivlii Caesaris Scaligeri, viri clarissimi poematum. pars altera, 1574, s.1.; BN: R/i 292.

200. Schottennius Hesso, Hermannus: Colloqvia sive confabvlationes tyronvm literatorvm... ad eodem nuper plusquam triginta conuiuiis le-

96 En el Índice aparece la fecha de edición 1544. 
pidissimis auctae ad haec quotidiani sermonis formulas cummuniores... adiecimus, 1547, Lugduni; BN: 2/55257.

201. Serranus, loannis: Ioannis Serrani, Pro vera ecclesiae catholicae autoritate defensio: aduersus loannis Hasy lesuitae disputationes, sacrae antiqvitatis iudicio simplicissime explicata..., 1594, Nemausi; BN: 2/69698.

202. Silvestris de Prierio: Sylvestrina summa, qua summa summarum erito nuncupatur, 4., 1569 , Amberes; BN: 6/i2663.

203. Silvestris de Prierio: Sylvestrina summae, quae summa summarum merito nuncupatur, pars prima, 1546, Lugduni; BN: 2/47480.

204. Simlerus, losia: De vera lesv Christido mini et servatoris nostri secundum humanam naturam in his terris praesentia, orthodoxa \& breuis expositio, losia Simlero Tigurio auctore, 1578, Tiguri; BN: 3/5020.

205. Simonis, Simoni: Simonis Simonii Lvcensis Med. et phil. doct. et profes. lipsensis. Antischegkianorvm liber vnus, 1570, Basileae; BN: 3/36957.

206. Sleidanus, Iohann: Ioan Sleidani De statv religionis et reipublicae, Carolo Quinto Caesare commentarii, 1555, Argentorati; BN: 2/69208.

207. Sleidanus, lohann: loan Sleidani, de qvatvor summis imperiis, libri tres, in gratiam iuuentutis confecti, 1556, Argentorati; BN: R/8697.

208. Snellius, Rudolphus: Rudolphi Snellii veteraquitanis Commentarius doctissimus in dialecticam Petri Rami, forma dialogi conscriptus; in quo artis praecepta cum exemplis analyticé explicantur..., 1595, Herbonae; BN: 3/19484.

209. Socinus, Faustus: Mini Celsi Senensis De haereticis capitali supplicio non afficiendis/ Adiunctae sunt euisdem argumenti Theodori Bezae \& Andreae Dvditii epistolae duae contrariae..., 1584, s.I.; BN: U/8035.

210. Stanihurstus, Richardus: Richardi Stanihursti dublinensis De rebvs in Hibernia gestis libri quattvor. Ad carissimum suum fratem, clarissimumque virum, P. Plvnketvm, Dominum Baronem Dunsaniae. Accessit his libris Hibernicarum rerum appendix ex Silvestro Giraldo Cambrensi..., 1584, Antuerpiae; BN: 2/55343.

211. Strigalius, Victorinus: In Epistolas dominicales explicationes Victorini Strigelii nunc primum in lucem editae opera \& studio Christophori Pezelii. sacrae Theologiae doctoris, 1584, Neapoli Palatinorum; BN: 3/17092.

212. Telesius, Bernardinus: Bernardini Telesii consentini De rerum natura iuxta propria principia, liber primus \& secundus, denuo editi, 1570 , Neapoli; BN: 2/66722. 
213. Turre Cremata, lohannis: Expositio in psalterium reuerendissimi D.d. Iohannis Yspani de Turre Cremata. Denundantur parrhisiis in vico sancti lacobi sub signo Sancti Claudii, 15(roto) ${ }^{97}$, s.l.; BN: R/23685.

214. Vadianus, loachimus: loachimi Vadianiconssangallensis Aphorismorum libri sex de consideratione Eucharistiae... de sacramentis antiquis \& novis... praeterea qualis fuerit ritus Coenae veteribus..., 1585, Tiguri; BN: $3 / 18683$.

215. Valla, Lavrentius: Laurentii Vallae elegatiarum latinae linguae libri sex/Eiusdem de reciprocatione sui \& suus, libellus... ab loanne Raenerio emendata omnia, 1548, Lugduni; BN: 2/7867.

216. Valverde Gandia, Bartolomeus: Ignis pvrgatorivs post hanc vitam, ex Graecis \& Latinis Patribus Orthodoxis, Haebreorumque doctissimis, ac uetustissi, assertus/ a Bartholomaeo Valuerdio \& Gandia Villenate. Accessit eiusdem pro Igne Purgatorio, Sanctorum intecessione..., 1581, Patavii; BN: R/30420-1.

217. Vergerius, Pietrus Paolus: Concilium non modo Tridentinum, sed omne Papisticum, perpetuo fugiendum esse omnibus piis, autore Vergerio, 1553, Tubingae; BN: 3/41003.

218. Vigelius, Nicolaus: Constitvtiones Carolinae Pvblicorum ludiciorum, in ordinem redactae cumque iure communi collatae, per Nicolavm Vigelivm iurisconsultum, Inserta item \& in ordinem redacta est Constitutio Carolina de fracta pace..., 1590, Basileae; BN: 2/6500.

219. Vigelius, Nicolaus: Nicolai Vigelii de Dreisa Hessorum iurisconsulti, Ivris fevdalis, tam controuersi, quam certi, liber unus: nunc denuò $a b$ autore auctus \& recognitus, 1584, Basileae; BN: 2/64842-1.

220. Viscontius, Pietrus: Qvaestio theologica de complice revelando, vel ne, in confessiones sacramentali. Per quvam necessaria, et vtilis: difficillima quidem, ac subitlissima..., 1594, Cremonae; BN: 2/50176.

221. Wild, lohanes ${ }^{98}$ : lobi historiae docta et catholica explicatio in CXIIII conciones eleganter distribvta.../ Per R. Patrem D. loannem Ferum... pro concione enarrata,1571, Coloniae; BN: 3/56710.

222. Willichius, lodocus: Vrinarvm probationes $D$. lodoci Wilichii.../ illvstratae scholis medicis, Hieronymi Revsneri... in qvibvs principia solidae Vroscopiae ad solidae Philosophiae fontes reuocantur... His acces-

97 En el Índice sin fecha.

98 Según el Índice anónimo. 
sere variae matularum delineationes, atque genuini urinarum colores, 1582, Basileae; BN: 3/35669.

223. Zvingerus, Theodorus: Methodvs apodemica in eorvm gratiam, qvi cum fructu in quocumque; tandem uitae genere peregrinari cupiunt a Theod. Zvingero, basiliense typis delineata..., 1577, Basileae; BN: $3 / 27422$. 